\title{
Sensors in Spray Processes
}

\author{
P. Fauchais and M. Vardelle
}

(Submitted August 6, 2009; in revised form January 21, 2010)

\begin{abstract}
This paper presents what is our actual knowledge about sensors, used in the harsh environment of spray booths, to improve the reproducibility and reliability of coatings sprayed with hot or cold gases. First are described, with their limitations and precisions, the different sensors following the in-flight hot particle parameters (trajectories, temperatures, velocities, sizes, and shapes). A few comments are also made about techniques, still under developments in laboratories, to improve our understanding of coating formation such as plasma jet temperature measurements in non-symmetrical conditions, hot gases heat flux, particles flattening and splats formation, particles evaporation. Then are described the illumination techniques by laser flash of either cold particles (those injected in hot gases, or in cold spray gun) or liquid injected into hot gases (suspensions or solutions). The possibilities they open to determine the flux and velocities of cold particles or visualize liquid penetration in the core of hot gases are discussed. Afterwards are presented sensors to follow, when spraying hot particles, substrate and coating temperature evolution, and the stress development within coatings during the spray process as well as the coating thickness. The different uses of these sensors are then described with successively: (i) Measurements limited to particle trajectories, velocities, temperatures, and sizes in different spray conditions: plasma (including transient conditions due to arc root fluctuations in d.c. plasma jets), HVOF, wire arc, cold spray. Afterwards are discussed how such sensor data can be used to achieve a better understanding of the different spray processes, compare experiments to calculations and improve the reproducibility and reliability of the spray conditions. (ii) Coatings monitoring through in-flight measurements coupled with those devoted to coatings formation. This is achieved by either maintaining at their set point both in-flight and certain spray parameters (spray pattern, coating temperature...), or defining a good working area through factorial design, or using artificial intelligence based on artificial neural network (ANN) to predict particle in-flight characteristics and coating structural attributes from the knowledge of processing parameters.
\end{abstract}

Keywords cold spray, particles in-flight, sensors, suspension spraying, thermal spray

\section{Introduction}

Conventional thermal spray processes (Ref 1-3) use different types of guns: flame, high-velocity oxyfuel flame (HVOF), high-velocity air flame (HVAF), detonation, plasma (produced by either direct current arc or RF discharge), and wire arc. More recently, the cold spray process has shown up where ductile particles in a solid state are plastically deformed, the previously deposited particles being further consolidated through the impact of the incoming ones. In spray applications, especially for industrial production, it is of primary importance to ensure constant quality of coatings as well as the reproducibility of their characteristics during production (Ref 4-7). This becomes mandatory as coatings are used in more and more demanding applications.

P. Fauchais and M. Vardelle, Laboratory Science of Ceramic Materials and Surface Treatment Processes, SPCTS, UMR 6638 CNRS, University of Limoges, 123 Rue Albert Thomas, 87060 Limoges Cedex, France. Contact e-mail: michel.vardelle@ unilim.fr.
Up to the mid-nineties, conventional spray processes were controlled by an iterative procedure (Ref 8): definition of process parameters, spraying, and evaluation of samples. The procedure was repeated until certain standards were obtained and the parameter setting was padlocked. Unfortunately, spray guns are sensitive to aging: nozzle wear in HVOF, or HVAF spraying, or cold spray, electrodes wear in plasma spraying, small displacement of the injector, its partial clogging... Such variations practically induce almost no apparent change of the macroscopic spray parameters. For example in combustion spray guns, combustible gas flow rates, carrier gas flow rate... do not vary with a slight injector clogging. In d.c. plasma spraying electrodes wear results in the voltage reduction, thus in power level reduction, the power source being a current source. In this case, the power level is kept constant by either increasing the arc current or the secondary gas flow rate. However, certain modifications (such as the hydrogen percentage increase) can induce rather important changes in particle parameters in flight with the modification of their trajectories, temperatures, and velocities (Ref 9). Indeed, keeping the power constant is not necessarily the most efficient way to accurately control the process.

The importance of controlling in-flight hot particle parameters, instead of macroscopic ones, was demonstrated in laboratories during the eighties and nineties. Rather sophisticated measuring devices were used such as laser Doppler anemometry (LDA) for particle velocities and phase Doppler shift to also measure their diameters, 


\begin{tabular}{|c|c|c|c|}
\hline \multicolumn{4}{|c|}{ Nomenclature } \\
\hline \multicolumn{2}{|r|}{ Latin Alphabet } & \multirow{2}{*}{$\begin{array}{l}\lambda \\
\rho \\
\rho_{\mathrm{I}}\end{array}$} & \multirow{3}{*}{$\begin{array}{l}\text { wavelength }(\mathrm{nm}) \\
\text { gas specific mass }\left(\mathrm{kg} \cdot \mathrm{m}^{-3}\right) \\
\text { liquid or suspension specific mass } \\
\left(\mathrm{kg} \cdot \mathrm{m}^{-3}\right)\end{array}$} \\
\hline$d_{\mathrm{L}}$ & liquid jet or drop diameter $(\mu \mathrm{m})$ & & \\
\hline$m$ & surface height mean value $(\mathrm{m})$ & & \\
\hline$P$ & plasma torch power $(\mathrm{kW})$ & \multirow{2}{*}{$\sigma_{\mathrm{L}}$} & \multirow{2}{*}{$\begin{array}{l}\text { liquid or suspension surface tension } \\
\left(\mathrm{J} \cdot \mathrm{m}^{-2}\right)\end{array}$} \\
\hline$P_{\text {eff }}$ & $\begin{array}{l}\text { power dissipated in the plasma forming } \\
\text { gas }\left(P_{\text {eff }}=P-Q_{\text {wat }}\right)(\mathrm{kW})\end{array}$ & & \\
\hline$Q_{\text {wat }}$ & power lost in the cooling water $(\mathrm{kW})$ & \multirow{2}{*}{\multicolumn{2}{|c|}{ Abbreviations }} \\
\hline SK skewness & $S_{k}=\frac{1}{\sigma^{3}} \int_{-\infty}^{+\infty}(z-m)^{3} \phi(x) d x$ & & \\
\hline$t_{\mathrm{i}}$ & induction time (s) & ANN & artificial neural network \\
\hline$T_{\mathrm{p}}$ & particle temperature $(\mathrm{K})$ & APS & atmospheric plasma spraying \\
\hline$T_{\mathrm{t}}$ & transition temperature $(\mathrm{K})$ & $\mathrm{CCD}$ & coupled charged device \\
\hline$v$ & gas velocity $\left(\mathrm{m} \cdot \mathrm{s}^{-1}\right)$ & CFD & computational fluid dynamic \\
\hline$v_{\mathrm{c}}$ & critical velocity $\left(\mathrm{m} \cdot \mathrm{s}^{-1}\right)$ & d.c. & direct current \\
\hline \multirow[t]{2}{*}{$v_{\mathrm{L}}$} & liquid or suspension injection velocity & D-gun & detonation gun \\
\hline & $\left(\mathrm{m} \cdot \mathrm{s}^{-1}\right)$ & i.d. & internal diameter \\
\hline$v_{\mathrm{p}}$ & particle velocity $\left(\mathrm{m} \cdot \mathrm{s}^{-1}\right)$ & I.R. & infra red \\
\hline$V_{\mathrm{m}}$ & time averaged voltage $(\mathrm{V})$ & LDA & laser Doppler anemometry \\
\hline$x$ & sampling length $(\mathrm{m})$ & LTE & local thermodynamic equilibrium \\
\hline \multirow[t]{4}{*}{$z$} & surface height $(\mathrm{m})$ & LVDT & linear variable differential transformer \\
\hline & & HVOF & high-velocity oxyfuel flame \\
\hline & & HVAF & high-velocity air flame \\
\hline & Greek Alphabet & PFI & particle flux imaging \\
\hline \multirow[t]{3}{*}{$\Delta U$} & velocity difference between hot gases & PSI & particle shape imaging \\
\hline & and liquid jet or drops $\left(\Delta U=v-v_{\mathrm{L}}\right)$ & $\mathrm{RF}$ & radio frequency \\
\hline & $\left(\mathrm{m} \cdot \mathrm{s}^{-1}\right)$ & SDC & spray and deposit control \\
\hline$\Delta V$ & voltage fluctuations $(\mathrm{V})$ & VPS & vacuum plasma spraying \\
\hline \multirow[t]{2}{*}{$\phi(x)$} & the distribution function of the surface & YPSZ & yttria partially stabilized zirconia \\
\hline & heights & YSZ & yttria-stabilized zirconia \\
\hline
\end{tabular}

fast pyrometers (with response time as short as $100 \mathrm{~ns}$ ) (Ref 10-12), and also CCD cameras for the detection of the hot particle trajectories distribution within the plasma jet. However, such measurements were far to be usable in the harsh environment of spray booths. It is only at the end of the nineties (Ref 13) that a commercially available in-flight particle condition (temperature, velocity, and diameter) monitoring system, the DPV-2000 ${ }^{\circledR}$ System (Tecnar Automation, Quebec, CN) was developed, based on the work of Moreau et al. (Ref 14). Almost in parallel, an imaging system for in-flight particle temperature, $T_{\mathrm{p}}$, and velocity, $v_{\mathrm{p}}$, measurements the Spray Watch ${ }^{\circledR}$ was developed by Oseir, based on the work of Vattulainen et al. (Ref 4). These devices were the first that could work in the harsh environment of spray booths. They allowed monitoring the effect of the conventional spray parameters (gas flow rates, nozzle internal diameter, power level for plasma spray torches, injection conditions, particles size distribution and morphologies...) onto the in-flight particle parameters. Many works have been devoted to the linkage between in-flight particle measurements and coating properties, see for example Ref 5, 7, 14-20. If such measurements have led to a drastic enhancement in our understanding of the process and improvement of coatings reproducibility and reliability ( $\operatorname{Ref} 5,7$ ), the linkage to coating properties is still some sort of enigma.
In the following, will be presented successively:

- Sensors to measure:

- in-flight parameters of hot particles, cold ones, suspension or solution spraying;

- other key parameters such as substrate temperature, stresses generation during spraying, heat flux from the hot gases, non-symmetrical plasma jet temperatures.

- Then, the way these sensors are used will be discussed with especially:

- the influence of the macroscopic spray parameters on the in-flight particle ones, measurements that have demonstrated their importance in improving coating reproducibility and reliability;

- the different attempts to monitor on-line certain coating properties with sensors.

\section{Sensors Used}

In conventional spray processes, the flux emitted or scattered by hot particles must be higher than that of the 
radiation from the hot gases. For example with plasma jets, measurements of the radiation emitted by hot particles are only possible in the plasma plume where the plasma temperature is below $6000 \mathrm{~K}$.

Two types of sensors exist: those fixed on the spray torch and those fixed aside of it. As the first ones are moved with the torch, they record continuously the measured parameters and any variation is instantly detected. Thus, the operator or the closed-loop feedback controller can react at once to correct the problem. Of course, these sensors must be rather light $(<1 \mathrm{~kg})$ and small $\left(<400 \mathrm{~cm}^{3}\right)$. When the sensor is fixed aside, the torch is driven in front of it after a given spray period, usually a few tens of minutes. Thus, problems cannot be detected on-line and corrected correlatively.

For sensors different techniques are considered:

- Local measurements with a small measurement volume, which can be below $1 \mathrm{~mm}^{3}$, coupled with relatively high-speed detectors and electronics with band widths on the order of 0.1 to $1 \mathrm{MHz}$ or greater. In this case, the observation of a single particle is possible (Ref 10-12). A sufficient number (several thousand) of individual particles must be observed to achieve an adequate statistical representation of the means and standard deviations of temperatures, velocities, and diameters recorded. Such measurements usually require lightly loaded thermal spray processes and are often performed with particles mass flow rates lower than $0.5-1 \mathrm{~kg} / \mathrm{h}$. Of course, it is assumed that same results are obtained in real spray conditions, which is true as soon as no loading effect occurs. Moreover, recording times are generally at least of a few minutes.

- Large measurement volumes, containing a large number of particles at a given time. They are called ensemble measurements and they do not attempt to distinguish between individual particles. For example, the measurement volume consists of an approximately cylindrical chord, of few tens of $\mathrm{mm}^{3}$, through the spray pattern. This chord is preferably oriented in the plane of the injector so that the measurement is insensitive to the movement of the spray pattern relative to the measurement volume (Ref 12). Of course, such measurements only give mean values. Ensemble techniques work equally well for heavily loaded processes such as HVOF spraying and measurement times are a few seconds.

To illustrate the difference between both techniques, and also the fact that such in-flight measurements are not sufficient by themselves to explain coating properties, an example is presented below. Renouard-Vallet (Ref 21) aimed at spraying yttria (13 wt.\%)-stabilized-zirconia (YSZ) particles (fused and crushed with a size distribution between 5 and $22 \mu \mathrm{m}$ ) by vacuum plasma spraying (VPS) to produce dense electrolytes about $50 \mu \mathrm{m}$ thick. A PTF4 torch, equipped with a Laval nozzle, was used working with an $\mathrm{Ar}^{-\mathrm{H}_{2}}$ mixture (40 slm-6 slm), an arc current of $750 \mathrm{~A}$ in a soft vacuum chamber where the pressure was kept at $8 \mathrm{kPa}$. The in-flight particle temperatures distribution (measured with a DPV-2000 focused at the substrate location on the particle jet axis) is presented Fig. 1(a). As it can be seen it is rather broad: from about $1000{ }^{\circ} \mathrm{C}$ (limit of such measurements) to $4000{ }^{\circ} \mathrm{C}$ and many particles are un-melted (if the absolute calibration of the pyrometer is correct). The ensemble temperature measurement (with a Spray Watch), indicated as $T_{\mathrm{e}}$ in Fig. 1(a), is in good agreement with the mean temperature resulting from the distribution in this figure. However, for more precise comparison, distributions obtained from DPV-2000 all over the measurement volume of the Spray Watch and weighted by the particle frequency should have been determined (Ref 22). Particle velocities (DPV-2000) were $150 \pm 70 \mathrm{~m} \cdot \mathrm{s}^{-1}$. Correspondingly splats collected at the standoff distance of $175 \mathrm{~mm}$ on a substrate maintained at $550{ }^{\circ} \mathrm{C}$ presented different shapes, including partially melted particles, which shape was still rather blocky. According to statistical measurements, performed on about 1200 of them, their mean diameter was $25 \mu \mathrm{m}$, with a mean thickness of $4 \mu \mathrm{m}$, values corresponding to a flattening degree of 1.8 . Coatings were also kept at $550{ }^{\circ} \mathrm{C}$ during spraying (with the help of cryogenic cooling) and are presented in Fig. 2(a). Their porosity was $10.9 \%$ (measured by image analysis of their cross-sections) and their ionic conductivity was $1.9 \times 10^{-2} \mathrm{~S} \cdot \mathrm{m}^{-1}$ (that of

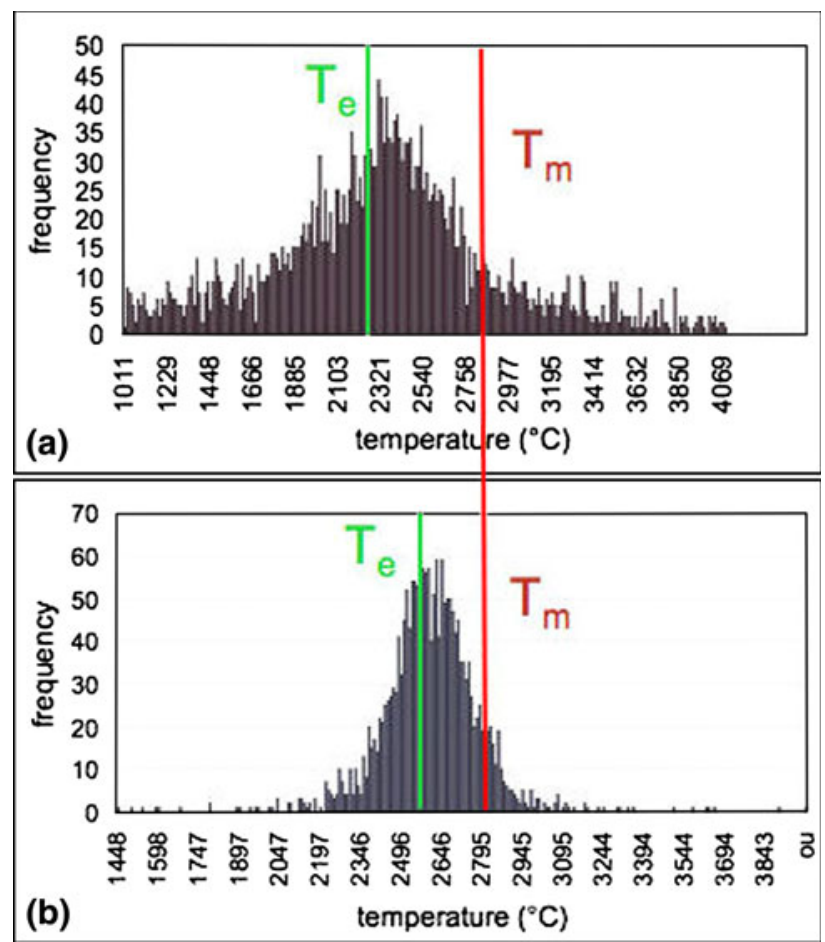

Fig. 1 In-flight temperatures distribution of yttria-stabilizedzirconia (YSZ) particles (fused and crushed, 5 and $22 \mu \mathrm{m}$ ) sprayed in soft vacuum with a PTF4 torch, Laval nozzle, Ar- $\mathrm{H}_{2}$ mixture (40 slm-6 slm), $750 \mathrm{~A}$, measurements performed with a DPV-2000 (statistical distribution) and a Spray Watch (ensemble value $T_{\mathrm{e}}$ ). The melting temperature, $T_{\mathrm{m}}$, is indicated. (a) Spraying performed without "windjet"; (b) with "windjet" (Ref 21) 
sintered YSZ being $1 \mathrm{~S} \cdot \mathrm{m}^{-1}$ ). Such a low ionic conductivity corresponds to rather poor contacts between layered splats. To get rid of un-melted particles and also of the tiny ones, a "windjet" (see its principle in Fig. 3) has been used, blowing argon orthogonally to the particle jet $3 \mathrm{~cm}$ ahead of the substrate. The corresponding particle temperatures distribution is shown in Fig. 2(b). Compared to that without "windjet", it is much more narrow, with values between about 2200 and $2950{ }^{\circ} \mathrm{C}$, and the mean

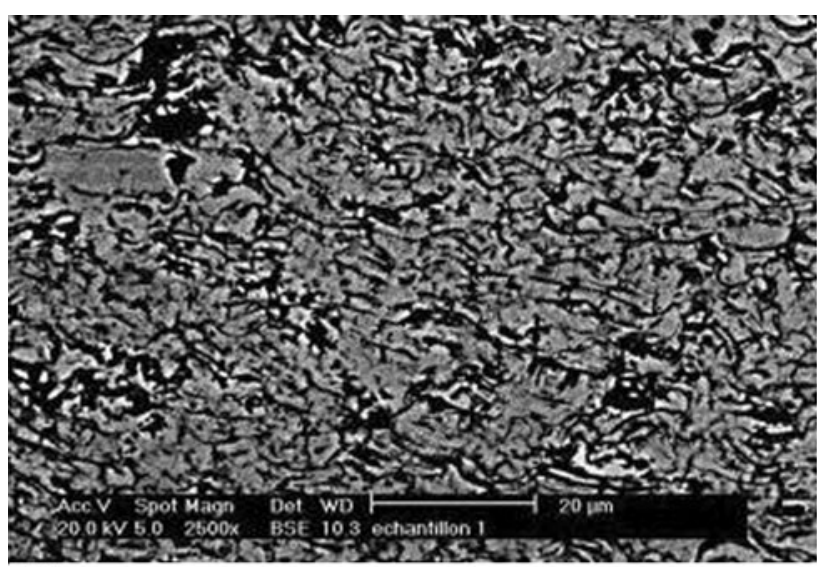

(a)

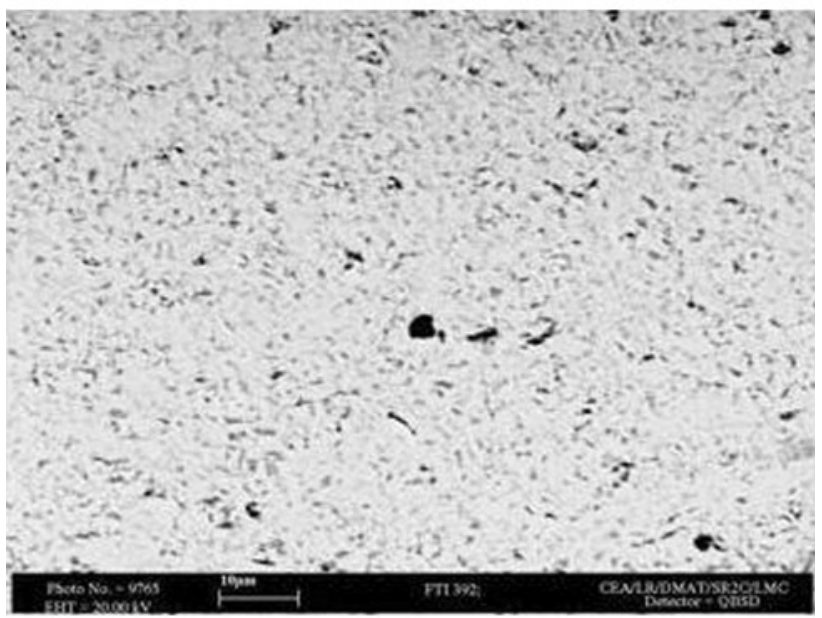

(b)

Fig. 2 Coatings obtained with the spray conditions of Fig. 1. (a) Spraying performed without "windjet"; (b) with "windjet" (Ref 21)

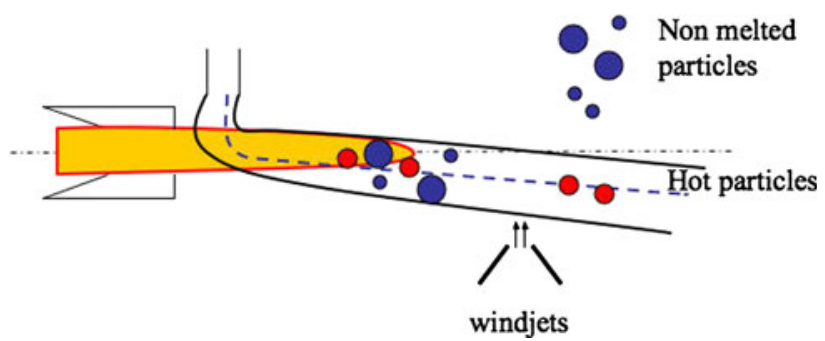

Fig. 3 Principle of the "windjet" (Ref 21) value is slightly higher. Here again ensemble temperature is in good agreement with it. The particle velocities (DPV2000) are now $80 \pm 25 \mathrm{~m} \cdot \mathrm{s}^{-1}$ : the high velocity tiny hot particles have been ejected by the "windjet", as well as the low velocity bigger cold particles. The hot particles with an intermediate size were slightly slowed down. Splats collected are rather close to disk shapes with a mean diameter of $30 \mu \mathrm{m}$, a mean thickness of $1.5 \mu \mathrm{m}$ corresponding to a flattening degree of 4 . The coating obtained with the "windjet" (also kept at $550{ }^{\circ} \mathrm{C}$ during spraying) is presented in Fig. 2(b). Compared to that without "windjet" it is denser $6.1 \%$ and its ionic conductivity is now $5 \times 10^{-1} \mathrm{~S} \cdot \mathrm{m}^{-1}$ corresponding to a much better contact between layered splats.

When looking at the ensemble temperatures, the values obtained with and without the "windjet" are close to the mean values deduced from DPV-2000. Spray Watch results correspond to average values representing a wide particle fraction in a comparatively large measurement volume. However, the differences between ensemble results with and without the "windjet" are much less informative than statistical measurements at a given location. Anyhow the drastic difference between coatings presented in Fig. 2(a) and (b) can only be explained by the important change in statistical temperature distributions together with splat distributions. These results allow understanding that the "windjet" eliminates most un-melted particles, as well as over-heated small particles.

\subsection{Hot Particles}

2.1.1 Velocity. During the seventies and eighties, several methods based on laser anemometry (Doppler effect or time-of-flight between two laser spots) were developed (Ref 10,11). These methods allowed measuring velocities in the bright core of a plasma jet, especially, with the timeof-flight method, for velocities higher than $500 \mathrm{~m} \cdot \mathrm{s}^{-1}$ in high power $(\approx 100 \mathrm{~kW})$ soft vacuum plasma spraying. However, they were not applicable to a dense stream of particles, as in spray conditions, and the complexity of alignment of optical components was not adapted to spray booths. Based on the work of Moreau (Ref 14), the commercially available particle condition monitoring system DPV-2000 was developed. When hot particles in the plasma jet or in combustion flame passed near the focal plane of the set-up, two slits in the sensing head generated a well-separated bi-peak pulse. Knowing the time between both pulses, and the distance between slots, the velocity was calculated, the waveforms of the thermal radiation signals being important for the measurement precision (Ref 13), which is generally better than 5\%. As the measurement volume is relatively small $\left(1 \mathrm{~mm}^{3}\right)$, the data are collected for individual particles and can subsequently be analyzed statistically. A new device called Accuraspray ${ }^{\circledR}$ has been developed (Ref 23) by Tecnar that, contrary to DPV-2000 ${ }^{\circledR}$, provides ensemble average data corresponding to a measurement volume $3 \mathrm{~mm}$ in diameter and $25 \mathrm{~mm}$ in length. When comparing particle velocities measured with the DPV-2000 to that delivered by Accuraspray-g3 system, it has to be considered that this

\section{.}


data is an average value representing a wide particle fraction in a comparatively large measurement volume. The measurement volume of the Accuraspray-g3 covers the entire width of the DPV-2000 one. As the Accuraspray-g3 system averages particle data on the whole measurement volume to one single representing value, hereby a weighting by the particle frequency must be performed (Ref 22) to ensure comparability. Thus, the local mean values of the particle data at each DPV-2000 grid point which is contained by the Accuraspray-g3 measurement volume must be weighted by the local particle flow rates to achieve one global mean value.

Another commercially available system was developed by OSEIR ${ }^{\circledR}$. The in-flight particle velocity is calculated by a time-of-flight method. The spray is imaged using a short exposure time (typically 5-10 $\mu$ s), which corresponds to 20-100 pixels on the CCD detector. During this period of time, particles travel certain distances and their velocities are deduced from the lengths and angles of their images on a CCD camera, after complex detection algorithms. Here again particles that are out of the focal plane are neglected. The area visualized has a width of 20 to $30 \mathrm{~mm}$ and a height between 16 and $24 \mathrm{~mm}$. Each measurement corresponds to a few particles, which position is recorded. It is thus possible to obtain, if necessary, velocities distribution of the few recorded particles in the measurement volume. However, in most cases, a mean value is calculated corresponding to an ensemble measurement.

In the Particle Shape Imaging ${ }^{\circledR}$ (PSI) system, the beam of a linear polarized Nd-YAG laser is split into two parts of equal intensity, which are crossed by mirrors in the focal plane of a long distance microscope (Ref 24). From the resulting image, an ICCD camera monitors a rectangular region. Particles outside of the depth of focus $(940 \mu \mathrm{m})$ are projected blurred or with interference effect and are eliminated. A particle crossing the measurement volume creates two shades in the image plane. The image acquisition starts when one particle enters the measurement volume and after an adjustable time delay. So that in the resulting picture, the particle distance from the trigger line corresponds to its velocity. Exposure times of $5 \mathrm{~ns}$ guarantee that particles with velocities up to $500 \mathrm{~m} / \mathrm{s}$ are sharply imaged. New cameras can achieve exposure times down to $0.1 \mu \mathrm{s}$. The precision of such measurements is better than $5 \%$.

2.1.2 Temperature. As for velocity, up to the midnineties, fast pyrometers were developed (Ref 10, 11) (response time of $100 \mathrm{~ns}$ ). They were mostly two-color pyrometers. However, contrary to velocity measurements, they are susceptible of errors in the absolute temperature that can reach $20 \%$ in some cases. This is particularly due to the effect of particle emissivity, often unknown or poorly known, and, for ceramic materials, absorption occurring in wavelengths around $1 \mu \mathrm{m}$ or over. The plasma light scattered by particles must also be taken into account (Ref 25). Of course, relative values of temperature can be measured with a precision of $5 \%$. Generally temperatures below $1200{ }^{\circ} \mathrm{C}$ are very difficult to measure with a reasonable precision.

The DPV $-2000^{\circledR}$ (measurement volume of about $1 \mathrm{~mm}^{2}$ ) allows measuring temperatures distribution of single particles. On the contrary, Accuraspray ${ }^{\circledR}$, also based on two-color pyrometer, give ensemble measurements. In the Spray Watch, the CCD collecting system is partly covered by two optical filter stripes, allowing the measurement of the radiation intensity of the particles flow in two wavelength ranges. It is also an ensemble measurement.

At last it must be underlined that all pyrometers must be very regularly calibrated (Ref 26).

2.1.3 Particle Size and Shape. If size measurements with Phase Doppler Shift method (assuming that particles are spherical) (Ref 10,11) were rather precise, it is not really the case with set-ups based on the radiation energy emitted at one wavelength by the hot particles as in DPV$2000^{\circledR}$. The difficulty is that it is necessary to assume spherical particles (not really the worst point of the method) and know precisely the emissivity of hot particles (that is the most critical point) at the temperature measured with the two-color pyrometer. Moreover, all particles are not necessarily detected by the system, especially the smallest one. Thus, the precision of this measurement is relatively poor (at the best $30 \%$ ). That is why such measurements must be calibrated, for example by collecting particles in water or in oil. Such calibration is especially important with wire arc spray, where the size distribution of droplets is unknown compared to other spray processes (Ref 27). In the experiment of Planche et al. (Ref 27), the static wire arc spray gun was directed towards the ground surface. A screen with a $2.5 \mathrm{~mm}$ diameter hole was placed at a distance of $160 \mathrm{~mm}$ from the gun. Underneath (40 mm) a tub of oil collected, during about $10 \mathrm{~s}$, particles passing through it. After oil filtering, captured particles were observed and analyzed using optical means. Optical analysis and statistical measurements of particle diameters were then performed. Afterwards, the DPV-2000 measurements were achieved at the same locations into the jet as those previously chosen for the capture of the particles. In this way, the calibration of the diameter parameter by the DPV could be made. Of course, diameter measurements are not possible with ensemble measurements.

With the Particle Shape Imaging set-up (Ref 24), different particle shapes and orientations can be resolved and the mean diameter of each particle determined with precision. The assumption of spherical particles is no more necessary.

2.1.4 Comparison of Ensemble and Single Particle Measurements. First of all it must be recalled that ensemble measurement is faster (a few seconds against a few minutes). Mauer et al. (Ref 22) have compared different measurements performed with DPV-2000 ${ }^{\circledR}$ and Accuraspray-g $2^{\circledR}$. This comparison was made after measuring and then weighting by the local particle flow rates the different local mean values of the particle data (temperatures and velocities) at each DPV-2000 grid point that is contained by the Accuraspray-g3 measurement volume. They found that results obtained with both systems were in good agreement, thus confirming the measurement accuracy of both. They have also identified some application limits for the DPV-2000 and the Accuraspray-g3 
diagnostic systems when using a few powder species. It is also reported that measurement of particle temperature close to plasma torch exit is generally more difficult to carry out by the Accuraspray-g3 than by the DPV-2000 system (Ref 28). That is probably due to the fact that the plasma radiation is dominant relatively to the particle radiation because of the much larger measurement volume of the Accuraspray-g3. At last, strong evaporation of particles might affect the identification of the particle radiation, especially when large volumes are analyzed.

Sampath et al. (Ref 7) found, comparing both measurement systems, that particle velocity measured from single and ensemble sensors can be correlated but careful consideration is required for understanding temperature results.

Streibl et al. (Ref 29) confirmed that many data are lost when using ensemble measurements instead of statistical ones. When considering the temperatures distribution of YSZ particles plasma sprayed (measured with DPV-2000), significantly different particle temperature distributions can be obtained for a given average value, as illustrated in Fig. 4.

A tri-modal structure can be observed in the temperature distribution from which a significantly melting peak can be extracted. This melting peak is at a constant temperature (for a given calibration setting of the pyrometer detector) and is independent of particle size, powder morphology, and process parameters. The second and third peaks correspond to the particle temperature distributions that relate to process conditions and can therefore be ruled out as a melting state indicator. It is thus of primary importance to look at the distributions themselves,

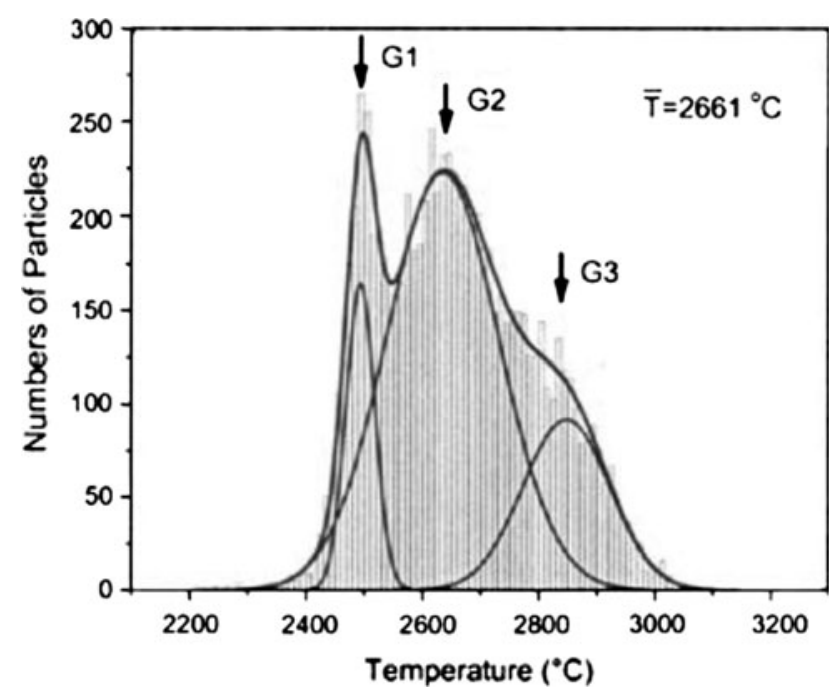

Fig. 4 Temperature distribution of particles (angular dense, $10-90 \mu \mathrm{m}, 8$ wt. $\% \quad \mathrm{Y}_{2} \mathrm{O}_{3}$-partially stabilized $\left.\mathrm{ZrO}_{2}\right)$ plasma sprayed with Sulzer Metco $7 \mathrm{MB}$ torch equipped with a ' $\mathrm{G}$ ' nozzle $8 \mathrm{~mm}$ in internal diameter. Spray parameters: $47.6 \mathrm{slm}$ of $\mathrm{N}_{2}, 5.6 \mathrm{slm}$ of $\mathrm{H}_{2}, 550$ A current and $3.7 \mathrm{slm}$ of carrier gas. The overall temperature distribution curve has been represented as a sum of three Gaussian curves and the individual peaks of these underlying curves have been label as 'G1', 'G2,' and 'G3' (Ref 29) and not an ensemble measurement, to draw conclusions on the melting state of particles.

2.1.5 Particle Trajectories Distribution. Two types of injection, linked to the spray gun, are used: radial at the nozzle exit (internal or external) or axial (Ref 30). Many works have been devoted to radial injection in d.c. plasma jets or HVOF jets (Ref 6, 30-42). With radial injection, an optimum trajectory is obtained if the momentum imparted to particles by the hot gases jet is close to their own momentum. The hot gases momentum is linked to their momentum density $\rho v^{2}$ where $\rho$ is their specific mass and $v$ their velocity. This quantity varies along the particle penetration trajectory: velocities and temperatures are increasing from the jet fringes to its centre, but $\rho$ is decreasing correspondingly (by less than a few tens of \%). The momentum of particles injected varies with their injection velocity and their mass. The particles injection velocity is imparted, for a given injector internal diameter, by the carrier gas flow rate. According to collisions between particles and the injector wall or between themselves, as well as the high Reynolds number of the carrier gas (very turbulent flow), particles, whatever may be their size, have about the same velocity at the injector exit (Ref 30). It means that their size distribution must be as narrow as possible to limit trajectories dispersion. For example, a diameter ratio of 2 between the smallest and the biggest particles (narrow distribution) corresponds already to a ratio of 8 of their mass and thus their momentums! Of course, the morphology of particles, modifying their mass density, must also be considered (Ref 43). The injection velocity of particles must be adapted to their mean size and to the mean hot jet momentum density. The latter varies very fast, through the jet velocity, with the jet enthalpy. It means that for any slight change in the torch working conditions, the injection velocity, through the carrier gas flow rate, must be adjusted. Indeed, the carrier gas flow rate must not perturb the hot gas flow (Ref 42, 44). As its flow rate must be increased to increase particles mean velocity, it becomes difficult to inject particles with sizes below 5-10 $\mu \mathrm{m}$, especially those with a specific mass lower than $3000 \mathrm{~kg} \cdot \mathrm{m}^{-3}$.

Axial injection is used with different spray guns such as flame, some HVOF or HVAF, detonation, a few d.c. plasmas, all R.F. plasmas and Cold Spray. Axial injectors play also a key role (Ref 45-54) according to both their position and the particle injection velocity, especially when the gas flow velocity is low as in flame or RF torches (Ref 45, 51).

Thus, the control of hot and cold particle trajectories is as important as their temperatures and velocities that are strongly linked to their trajectories. This control can be achieved with the DPV-2000 ${ }^{\circledR}$, the Plume Spector ${ }^{\circledR}$, and the Accuraspray ${ }^{\circledR}$ of Tecnar. The hot particles distribution can also be measured with the Spray and Deposit Control $^{\circledR}$ (Ref 30, 55). The SDC ${ }^{\circledR}$ uses either a CCD camera or a photodiode array where the image of a section of the plasma jet plume is focused. A filter with a $3 \mathrm{~nm}$ band pass allows eliminating the most important part of the plasma plume light or that of combustion gases in HVOF. It is possible to record 4 images/s and, as the SDC is fixed

(1) 

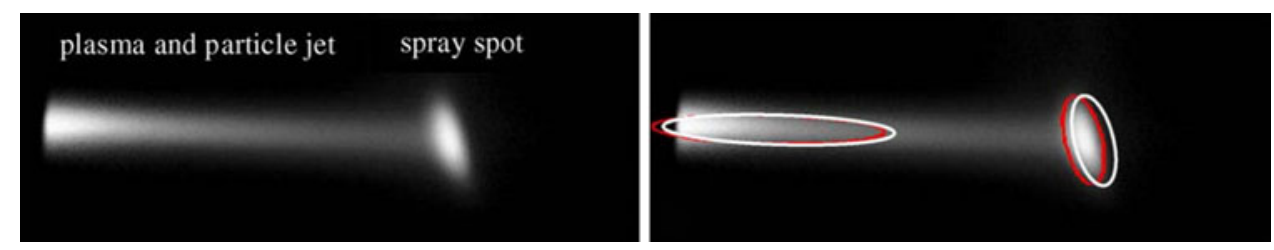

Fig. 5 (a) PFI-S image of a running process (left); (b) PFI-S image with two calculated ellipses (right) (Ref 24)

on the plasma torch or the HVOF gun, the particle trajectories can be continuously monitored. All these techniques, except the DPV-2000, are ensemble measurements. The Particle Shape Imaging ${ }^{\circledR}$ from Linspray (Ref 24), described in Sect 2.1.1 and 2.1.3, allows also determining the position of individual particles.

The Particle Flux Imaging ${ }^{\circledR}$ (PFI) from Linspray (Ref 24, 56), tested in plasma spraying, records the plasma jet close to the torch and the particle flux (ensemble measurement) in the plasma jet plume and also the spray spot in the last version. Using a CCD camera the very luminous plasma jet close to the torch, the less luminous particle flux in the downstream zone and the spray spot are imaged simultaneously (see Fig. 5a).

A PC reduces the information by finding lines of constant radiation intensity in the images of the hot plasma jet and of the particles flux. These lines can be approximated by ellipses. Their characteristics are typical for the state of the coating process and any variation of macroscopic parameters results in the particles ellipse displacement. This system allows also detecting the possible perturbation of hot gases jet by the carrier gas when radially injected. In this way, variations in the hot plasma jet as well as in the particle flux can be detected without a precise knowledge of exact physical plasma jet or particle parameters. An example of two ellipses (plasma jet and spray spot) is presented in Fig. 5(b). Of course, for plasma jets, due to their very high level of radiation, filters with different transmittivity must be used for plasma and particles.

The PFI ${ }^{\circledR}$ system, as the SDC ${ }^{\circledR}$, are moved attached to the gun and image continuously the whole area between the gun and the substrate surface, thus allowing an instant response to any change in spray conditions. The particles injection velocity, controlled by the carrier gas flow rate, must be adapted to the mean particle size of the distribution to achieve the optimum trajectory. This is illustrated in Fig. 6 for the radial injection of alumina particles into a d.c. plasma jet.

For the working conditions, the different radial distributions of the light emitted by hot particles reach a maximum for a carrier gas flow rate of $4.5 \mathrm{slm}$ (see Fig. 6a). The corresponding mean trajectories are represented in Fig. 6(b). Any change in the torch working conditions requires adapting the carrier gas flow rate to achieve the optimum trajectory. Out of the optimum trajectory fewer particles are treated in the plasma hot zone, but their mean temperature and velocity are not necessarily different from those obtained with trajectories close to the optimum one.

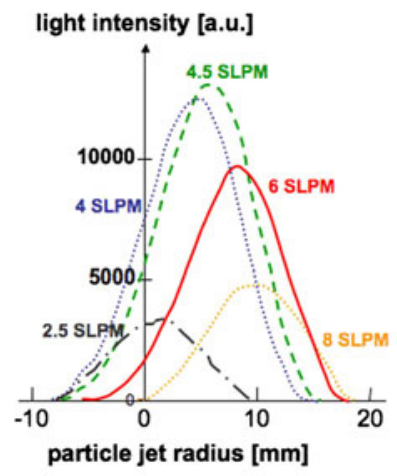

(a)

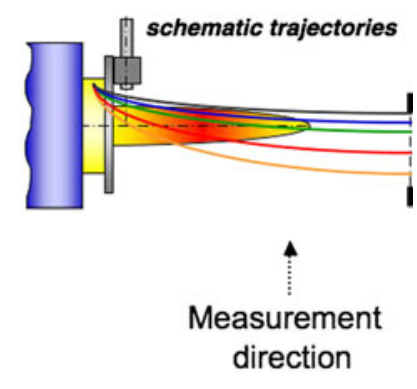

(b)

Fig. 6 Effect of carrier gas flow rate on the radial distribution of alumina particles $(22-45 \mu \mathrm{m})$ into an $\mathrm{Ar}-\mathrm{H}_{2}$ d.c. plasma jet (45 slm Ar, $15 \mathrm{slm} \mathrm{H}_{2}$, Peff $=20 \mathrm{~kW}$, injector i.d. $=1.75 \mathrm{~mm}$ ). (a) Light intensity emitted by hot particles distribution in a cross section of the plasma jet located $70 \mathrm{~mm}$ downstream of the anode-nozzle; (b) corresponding trajectories (Ref 30)

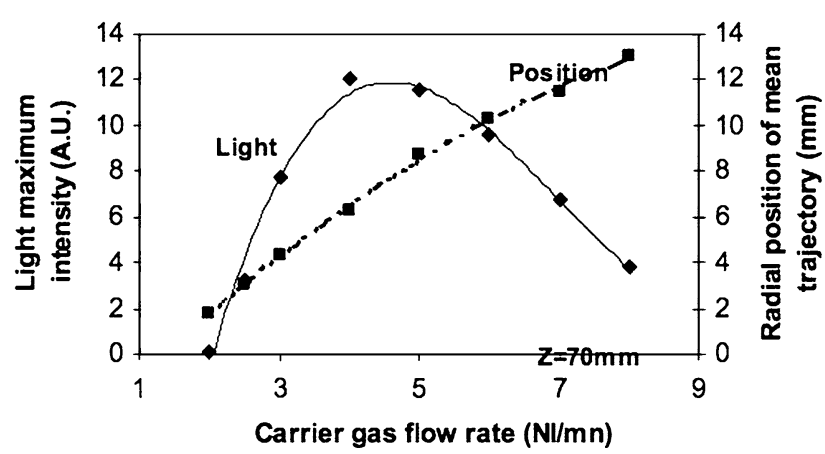

Fig. 7 Evolution with the carrier gas flow rate (argon) of the maximum intensity of the light emitted by the hot particles and of its position relatively to the torch axis. Spray conditions given in Fig. 6 (Ref 30)

The SDC also allows following the evolution, with the carrier gas flow rate, of the maximum of the signal emitted by hot particles as well as the position of this maximum relatively to the torch axis (see Fig. 7). The optimum trajectory corresponds to a mean trajectory of particles making an angle of $3.5^{\circ}$ with the torch axis and also induces the best temperature and velocity distributions.

Srinivasan et al. (Ref 5) have also emphasized the importance of particle trajectories. Figure 8 represents the influence of the injection optimization on the variability in 


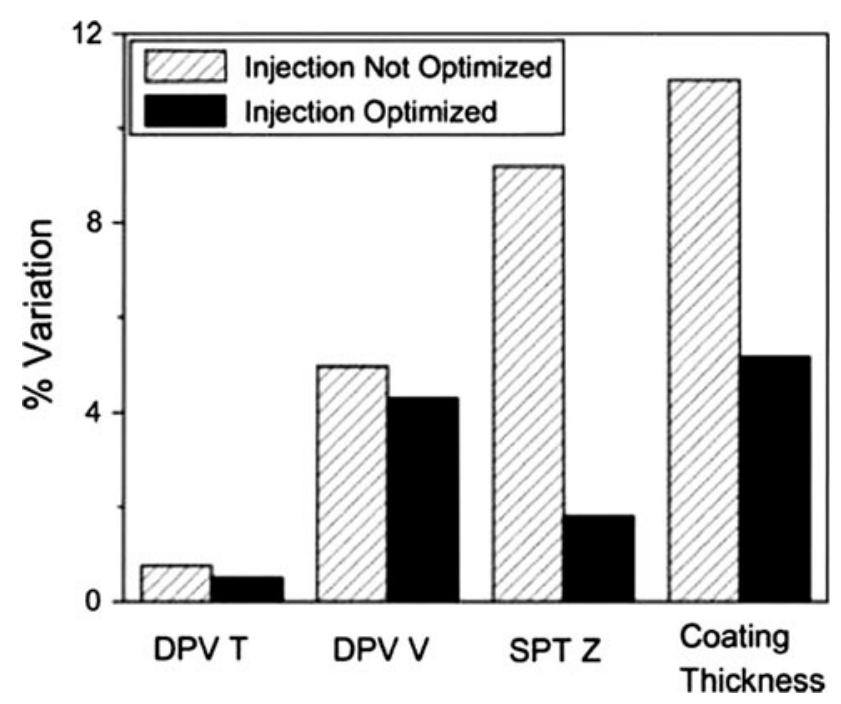

Fig. 8 Influence of injection optimization on the variability of particle mean temperature (DPVT) and velocity (DPVV), position of the hot particles jet (SPTZ) and coating thickness (YSZ particles), 10-75 $\mu \mathrm{m}$, APS 7 MB torch from Sulzer Metco with a $8 \mathrm{~mm}$ "G" nozzle working with a mixture $\mathrm{N}_{2}-\mathrm{H}_{2}$ (Ref 5)

particle parameters: temperature, velocity, and position of the hot particles jet and the coating thickness. If, apparently, for the mean values of temperatures and velocities the trajectory influence is not very important, it is quite different for the coating thickness with an important reduction in its variability. This is probably due to the fact that, for the optimum trajectory, more particles reach the optimum temperature and velocity, thus improving the deposition efficiency and correlatively increasing the coating thickness.

2.1.6 Time Resolved Measurements. As underlined in the previous section, the particles mean trajectory must be adapted to any change in the spray torch parameters. When d.c. plasma spraying, voltage fluctuations $\Delta V$ can be very high with the ratio $\Delta V / V_{\mathrm{m}}>1$ where $V_{\mathrm{m}}$ is the mean voltage. This is especially the case in the restrike mode, taking place with di-atomic gas in the plasma forming gases. As the plasma jet enthalpy can vary, with voltage fluctuations, in a ratio of 2 or more, its velocity, $v$, varies at least in the same ratio and then the momentum density $\rho v^{2}$ varies as the square of $v$. As the response time of the carrier gas is about $10 \mathrm{~Hz}$, while arc root fluctuations are in the $5000 \mathrm{~Hz}$ range, particle trajectories, and thus temperatures and velocities vary with the voltage fluctuation. For that Bisson et al. (Ref 57, 58) have synchronized the DPV $-2000^{\circledR}$ device with the torch voltage fluctuations. They used an electronic circuit that generates a pulse when the voltage reaches some specific level, pulse triggering the signal acquisition.

This is illustrated in Fig. 9 from Bisson et al. (Ref 58). They used the DPV-2000 and a comparator generating a pulse when the instant voltage exceeded a threshold. This pulse was used to trigger the DPV-2000 a specific time after the threshold is crossed and particle parameters were measured as functions of the time delay. For alumina

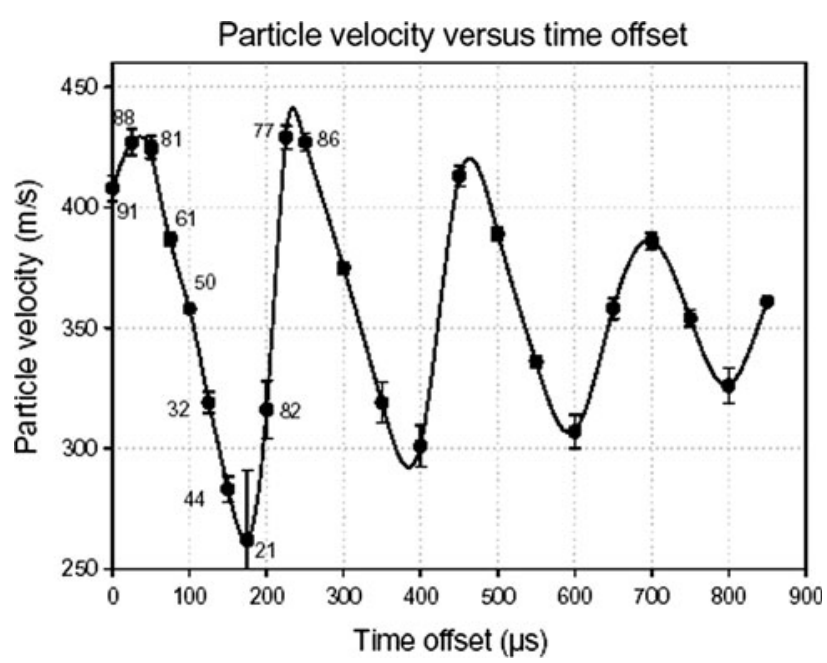

Fig. 9 Fluctuations of the velocity of alumina particles $(22-45 \mu \mathrm{m})$ sprayed with an $\mathrm{Ar}-\mathrm{H}_{2}$ plasma jet (Ar $35 \mathrm{slm}, \mathrm{H}_{2}$ $10 \mathrm{slm}, I=550 \mathrm{~A}$, and i.d. $7 \mathrm{~mm}$ ) as a function of time delay (Ref 58)

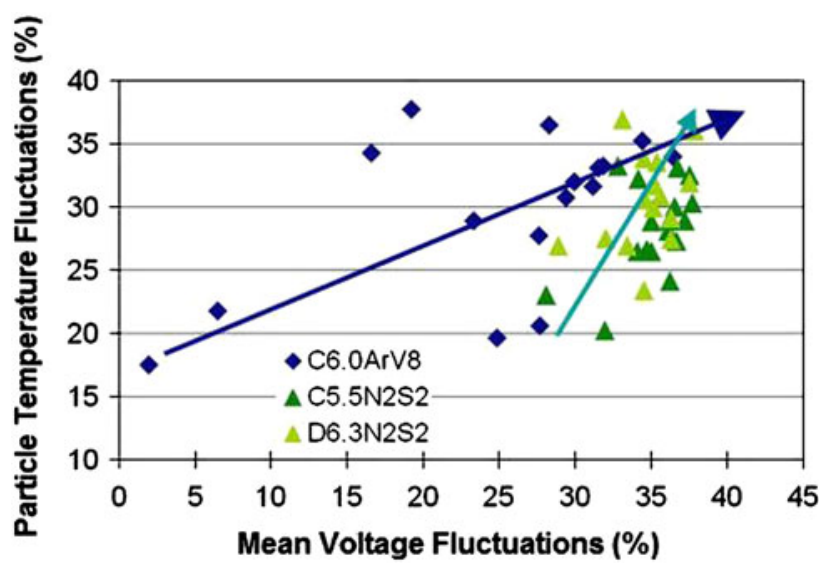

Fig. 10 Evolution with mean voltage fluctuations $\left(\Delta V / V_{\mathrm{m}}\right)$ of the mean particle temperature fluctuations for three different torches working with $\mathrm{Ar}-\mathrm{H}_{2}$ (PTF4) and $\mathrm{N}_{2}-\mathrm{H}_{2}$ (3 MB) (Ref 59)

particles, periodic variations of temperature (about $500{ }^{\circ} \mathrm{C}$ ) and velocity (around $200 \mathrm{~m} / \mathrm{s}$ ) were observed, as illustrated in Fig. 9 for particle velocities. The period of the cycles coincides with that of voltage fluctuations (period $220 \mu$ s or $f=4500 \mathrm{~Hz}$ ).

Recently, Nogues et al. (Ref 59) have developed a rapid bi-chromatic pyrometer system, triggered by the arc voltage fluctuations, and allowing a detection time of $2 \mu \mathrm{s}$ for a single particle. They have compared three plasma torches, one working with $\mathrm{Ar}-\mathrm{H}_{2}$ (PTF4 from Sulzer Metco) and two with $\mathrm{N}_{2}-\mathrm{H}_{2}$ (3 MB torches of Sulzer Metco with different plasma forming gases injectors and anode-nozzles). The voltage fluctuation frequency of the PTF4 torch is around $4000 \mathrm{~Hz}$ while that of the $3 \mathrm{MB}$ ones is about $6000 \mathrm{~Hz}$. Figure 10 shows the evolution with the mean voltage fluctuations of the particle temperature fluctuations. Whatever the torch configuration, the 
temperature fluctuation increases. It means that particles "follow" voltage fluctuations: the more important are the torch fluctuations, the more heterogenic is the particle treatment. The rapid pyrometer allows also obtaining the temperature FFT curves. The particle temperature fluctuation frequency follows that of arc voltage only in the case of the PTF4 torch working with argon-hydrogen mixtures. It means that voltage fluctuations have no direct influence on the particle treatment when using the $3 \mathrm{MB}$ plasma torch working with nitrogen-hydrogen mixtures. The particle velocity fluctuations increase with the mean voltage fluctuations for the $\mathrm{Ar}-\mathrm{H}_{2}$ plasma, while they decrease for the $\mathrm{N}_{2}-\mathrm{H}_{2}$ plasma in spite of larger mean voltage fluctuations. More works are necessary to achieve a better understanding of these phenomena.

\subsection{Cold Particles}

Following cold particle trajectories and velocities is also of primary importance for all spray processes. This can be achieved by illuminating all particles (cold and hot ones) with a laser to determine all particle trajectories and velocities. Then, results are compared with those obtained with hot particles (without laser illumination) to determine where cold particles travel and with what velocities. For conventional thermal spray processes it allows optimizing the injector design and follow particles that have not penetrated in the hot gases jet core and travel in its fringes. For cold spray, particle velocities can be measured and their critical velocity determined if their diameter is also determined, which is not yet possible with the existing sensors if velocities are over $500 \mathrm{~m} \cdot \mathrm{s}^{-1}$. Velocity measurement is achieved by illuminating particles with a laser, which is scanned through the jet cross section, and measuring the bursts of scattered light as the particle flow pass the laser beam (Ref 30$)$. The particle velocity in cold spray process was measured by using laser two-focus anemometer (Ref 60). Jodoin et al. (Ref 61) have developed measurements of particles in cold spray process, using the Oseir Spray Watch ${ }^{\circledR}$ combining a fast shutter CCD camera with a high power pulsed laser diode (Hiwatch) to illuminate particles. The camera exposure time is between $100 \mathrm{~ns}$ and $10 \mathrm{~ms}$ with a maximum of 7 frames/s. The diode laser produces a laser sheet (at $\lambda=808 \mathrm{~nm}$ ) with a width of $15 \mathrm{~mm}$ and a thickness of $1.5 \mathrm{~mm}$, the pulse length being in the 50-2000 ns range. The accuracy in velocity measurement is $1-10 \mathrm{~m} / \mathrm{s}$. It is also possible to use the DPV-2000 with particles illuminated by a laser diode (7 W, $\lambda=830 \mathrm{~nm})($ Ref 62, 63).

Two examples will be presented to illustrate the interest of such measurements: the optimization of the powder injection and the determination of critical velocity in cold spray.

2.2.1 Powder Injection. One of the problems, especially with plasma jets where heat fluxes can be very high close to the plasma jet core, is to find the right distance between the injector extremity and the jet core. If the distance is short, all particles exiting the injector (with cone-shaped trajectories, generally with an angle between 10 and $30^{\circ}$ ) will penetrate within the plasma jet. However, clogging may occur due to the heat flux from the plasma. The solution is then to position the injector farther from the jet as illustrated in Fig. 11(a). In this case, as schematically drawn in Fig. 11(a), particles bypass the jet. Those that have reached the other side of the jet with a low velocity are sucked down by the fast flowing hot gases and entrained in the jet fringes. They will certainly not be melted but they can be sufficiently heated to stick to the hot successive passes deposited creating defects between them. Two solutions are possible: use a water-cooled wall injector, which can be disposed closer to the plasma jet, or constricting the particle jet with a double flow injector, as represented in Fig. 11(b). The gas flow rate around the injector has to be adapted to the carrier gas flow rate (Ref 30). This is illustrated in Fig. 12(a), where the cold particle flow exiting the injector, $1.8 \mathrm{~mm}$ in internal diameter with no gas injected around, is illuminated by the laser. The same injector, but with 3 slm injected around, results in a good constriction of the powder jet.

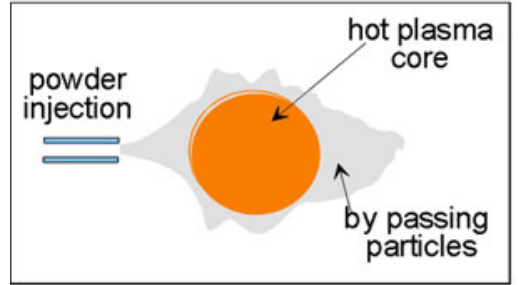

(a)

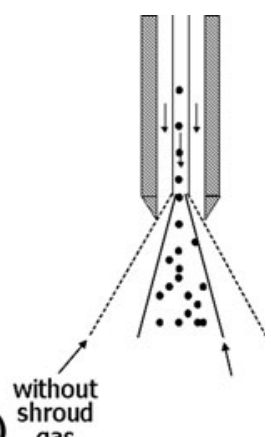

(b) $\underset{\text { gas }}{\text { shrout }}$
Fig. 11 (a) Scheme of the powder injection with the injector sufficiently far from the hot plasma core for a part of the powder by-passing the jet; (b) double flow injector (Ref 30)

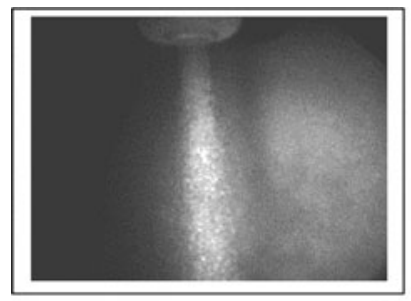

(a) Conventional injector

(b) Double flux injector

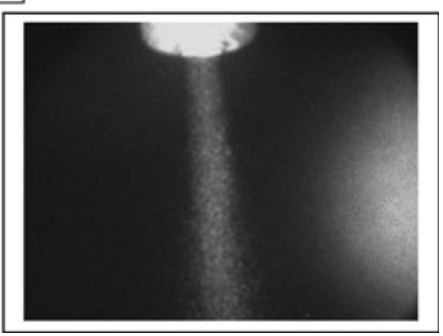

Fig. 12 YSZ particles $(22-45 \mu \mathrm{m})$ illuminated by a laser sheet at the injector exit: (a) conventional injector and (b) double flux injector (Ref 30) 


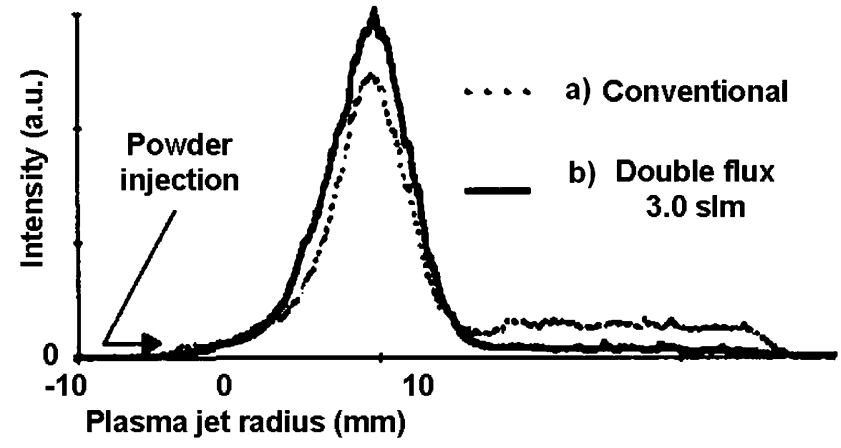

Fig. 13 Alumina particles radial distribution $20 \mathrm{~mm}$ downstream the double flow injector: (a) $6 \mathrm{slm}$ argon in the central part of the injector and $0 \mathrm{slm}$ around it; (b) $3 \mathrm{slm}$ in the central part of the injector and $3 \mathrm{slm}$ around it (Ref 30)

The effect of this constriction is presented in Fig. 13, with the hot and cold particles radial distributions, $20 \mathrm{~mm}$ downstream of the injector. In the right part of Fig. 13, for the conventional single injector, a flat distribution is observed, corresponding to particles bypassing the jet, as schematized in Fig. 11(a). In Fig. 13(a), the maximum signal of hot particles (similar to that presented in Fig. 6a), obtained with the single injector flow, resulted from a carrier gas flow rate of $6 \mathrm{slm}$ and its position is of course identical to that obtained with the laser (cold and hot particles). In Fig. 13(b), with the double flow injector, most of the particles bypassing the jet with a single flow injector are now penetrating it. It is also interesting to note that the maximum intensity of hot and cold particles is positioned at almost the same radial position as that obtained with the single flow injector. The double flow injector almost does not modify the particles mean trajectory. However, it must be noted that with the double flow injector, the carrier gas flow rate is only $3 \mathrm{slm}$, while that corresponding to the surrounding gas flow is $3 \mathrm{slm}$ (with the single injector this trajectory was obtained with $6 \mathrm{slm}$ ). In both cases (single and double flow injector), the mean trajectory is almost the same.

2.2.2 Cold Spray. Particle velocities, when cold sprayed, have been measured and compared to models (Ref 61, 64), to find the effect of substrate temperature on the formation mechanism of aluminium, zinc, and tin coatings (Ref 63), to study the coating build-up mechanisms and properties when cold-spraying aluminium and alumina particles to form cermets (Ref 62), and to determine the influence of the powder properties (Ref 65).

A complex problem is however to determine the critical velocity of a powder. This critical velocity corresponds to the beginning of the adherence of the impacting particles. However, a powder corresponds to a particle size distribution. When the smallest particles start to adhere, because they have reached their critical velocity, it is not necessarily the case of the bigger ones. The question is then what is the maximum diameter which can be deposited for the gun working conditions and how to determine it. What is currently admitted is that the critical

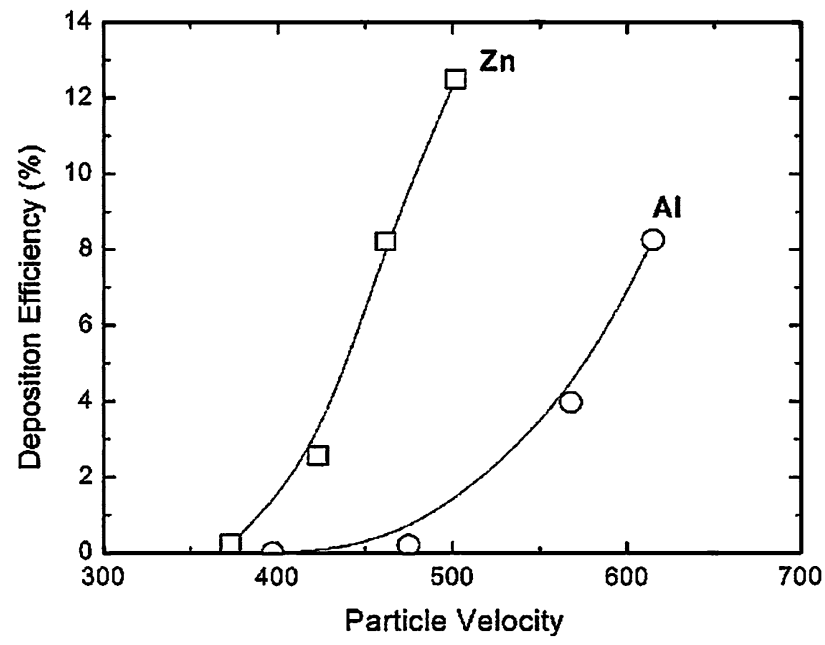

Fig. 14 Deposition efficiency as a function of the average particle velocity: $\mathrm{Al}$ and $\mathrm{Zn}$ particles with an average size of 36.2 and $10.6 \mu \mathrm{m}$ respectively. Powders, injected radially, were sprayed with low-pressure cold-spray system (SST, Centerline, ON, Canada) working with nitrogen at $0.62 \mathrm{MPa}$ and that can be heated in the gun region up to $500{ }^{\circ} \mathrm{C}(\operatorname{Ref} 63)$

velocity corresponds to that of the mean sized particles (mass distribution), which implies that the deposition efficiency is $50 \%$ when measuring the mean velocity (ensemble measurements). However, this method is timeconsuming because not only the mean particles velocity has to be measured but also the deposition efficiency. Moreover, it is sometimes difficult to reach a deposition efficiency of $50 \%$ !

For example, Legoux et al. (Ref 63) have performed such measurements for aluminum and zinc (Fig. 14). It can be seen that the deposition starts to be measurable for average velocities of about 400 and $500 \mathrm{~m} / \mathrm{s}$ for $\mathrm{Zn}$ and $\mathrm{Al}$, respectively. This study also shows that surface temperature at the impact point of a low-pressure cold-spray system can be significantly influenced by the process gas temperature. The deposition efficiency changes as a function of the process gas temperature because of the influence of this processing parameter both on the gas velocity and on the substrate surface temperature.

To avoid the deposition efficiency measurement, Raletz (Ref 66) has developed a method consisting in determining with the Spray Watch and the particles illuminated by the laser sheet, correlations existing between the impacting particles flux and those rebounding onto the substrate. As the velocity of the rebounding particle is rather low, compared to its impacting velocity (it can be ten times lower), the flux measurement is performed by taking into account all the bright spots on the screen. Contrary to what is done in conventional velocity measurement, with the Spray Watch, it is not necessary that each bright point is aligned with two other ones to be accounted for the flux, while for the impact velocity only three aligned points are considered. A typical result is shown in Fig. 15. 


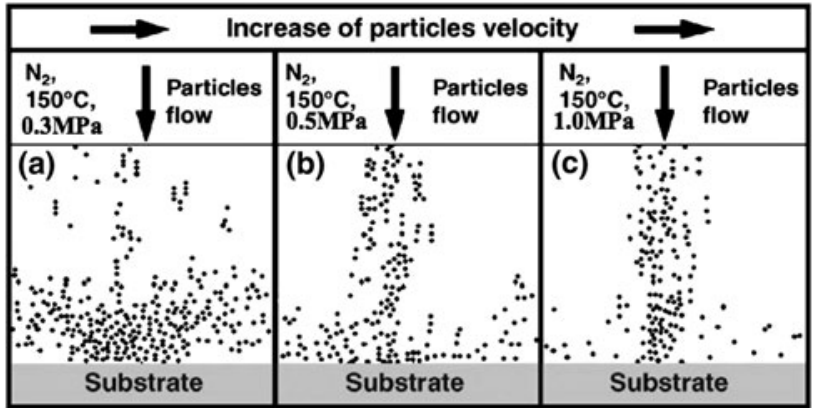

Cu particles on Cu particles

Fig. 15 Evolution with the mean impact velocity of the flux distribution of $\mathrm{Cu}$ particles impacting on a $\mathrm{Cu}$ substrate: images obtained with Spray Watch and laser sheet illumination (Ref 66)

As expected the particle flux distribution clearly depends on their impact velocity controlled by the spray conditions:

- In Fig. 15(a), the gas velocity is relatively low and the particle jet is not sufficiently focused. The concentration of rebounding particles close to the substrate is important and non-uniform.

- In Fig. 15(b) for these spray conditions, the jet is much better focused but the velocity is still below the critical one and the number of rebounding particles is almost that of the sprayed particles.

- In Fig. 15(c) for these spray conditions, the critical velocity is reached for most particles. The width of the jet is about that of case B but the number of rebounds is drastically reduced.

It is then possible, for the different velocities measured, to experimentally draw radial flux distribution curves representing the number of sticking particles. They are obtained by subtracting from the impacting particles number at each radial position the maximum value of the rebounding ones calculated in the jet fringes. For each curve, corresponding to each mean impact velocity, the deposition efficiency can be determined.

\subsection{Suspensions and Solutions}

There is a large development since the beginning of the millennium in suspensions and solutions plasma or HVOF sprayed (Ref 67-82). The main problem is to follow how the liquid jet or the liquid drops penetrate within the plasma or the HVOF jet. In radial injection, when the hot gases flow hits the liquid, first fragmentation takes place and then the resulting tiny droplets (a few $\mu \mathrm{m}$ in diameter) vaporize $(\operatorname{Ref} 67,68)$. Fragmentation times are about 2 to 3 orders of magnitude smaller than vaporization ones (Ref 67, 68). The set-up developed to observe the suspension penetration within the plasma jet (Ref 82) consists of a fast shutter camera (that of the Spray Watch) coupled with the laser sheet flash at $808 \mathrm{~nm}$. The image is triggered when the voltage reaches a given threshold. Figure 16

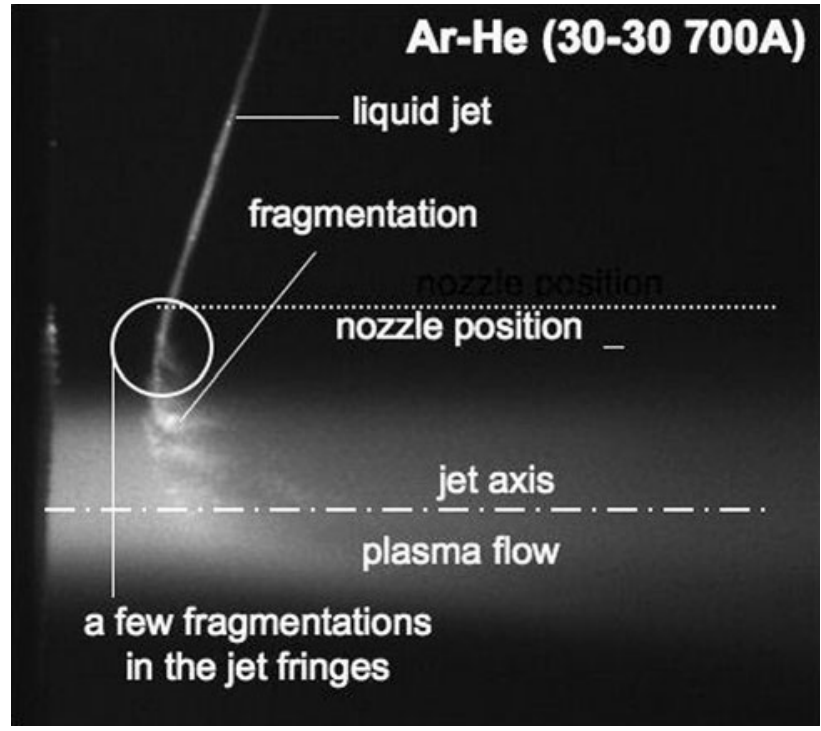

Fig. 16 Interaction plasma jet-ethanol suspension, image taken when the fluctuating voltage of the $\mathrm{Ar}-\mathrm{H}_{2}$ plasma was $65 \mathrm{~V}(\mathrm{Ar}$ $45 \mathrm{slm}, \mathrm{H}_{2} 15 \mathrm{slm}$, nozzle i.d. $6 \mathrm{~mm}, 500 \mathrm{~A}$ ). Liquid mechanically injected with a nozzle internal diameter of $150 \mu \mathrm{m}$ (Ref 82)

(Ref 82) represents the corresponding image obtained with a mechanical injection of an ethanol suspension injected into an $\mathrm{Ar}-\mathrm{H}_{2}$ plasma jet, image triggered for a $65 \mathrm{~V}$ voltage. The dashed line in the figure top corresponds to the anode nozzle position. The distance between the torch axis and the injector is $23 \mathrm{~mm}$ and, just before entering the plasma jet, weak instabilities of the liquid jet can be observed with a wavelength of about $900 \mathrm{~nm}$. Upon its penetration into the jet, and unfortunately also in its fringes, the liquid jet is broken at the neck of its own instabilities by the shear stress produced. Several clouds of material (liquid and/or solid) within the plasma jet are visible in Fig. 16. However, it must be kept in mind that, according to the image size and the number of pixels $(600 \times 600)$, one pixel represents about $30 \mu \mathrm{m}^{2}$. It is thus impossible to see fragmented droplets that sizes are below $2 \mu \mathrm{m}$ in diameter. Clouds are composed of a compact head of suspension and, behind it, some sort of tail with tiny droplets and/or solid particles resulting from the fragmentation that keeps going. The distance between clouds corresponds to $900 \mu \mathrm{m}$, which means that the liquid initial velocity (here $26.6 \pm 2 \mathrm{~m} / \mathrm{s}$ ) is kept.

To obtain more information on the plasma and liquid jet interaction, several images taken in the same conditions (in about $1 \mathrm{~s}$ ) were superposed in order to eliminate the plasma high luminosity masking the low one of the liquid (Fig. 17) (Ref 82). Before being superposed, images were filtered to eliminate the plasma luminosity. The final image (Fig. 17c), corresponding to 10 superposed images, allows determining two characteristic angles of the liquid penetration: the dispersion angle of the liquid in the plasma flow $(\theta)$ and the deviation angle of the suspension jet $(\alpha)$. Thus, such images permit optimizing the liquid penetration by adjusting its velocity. 

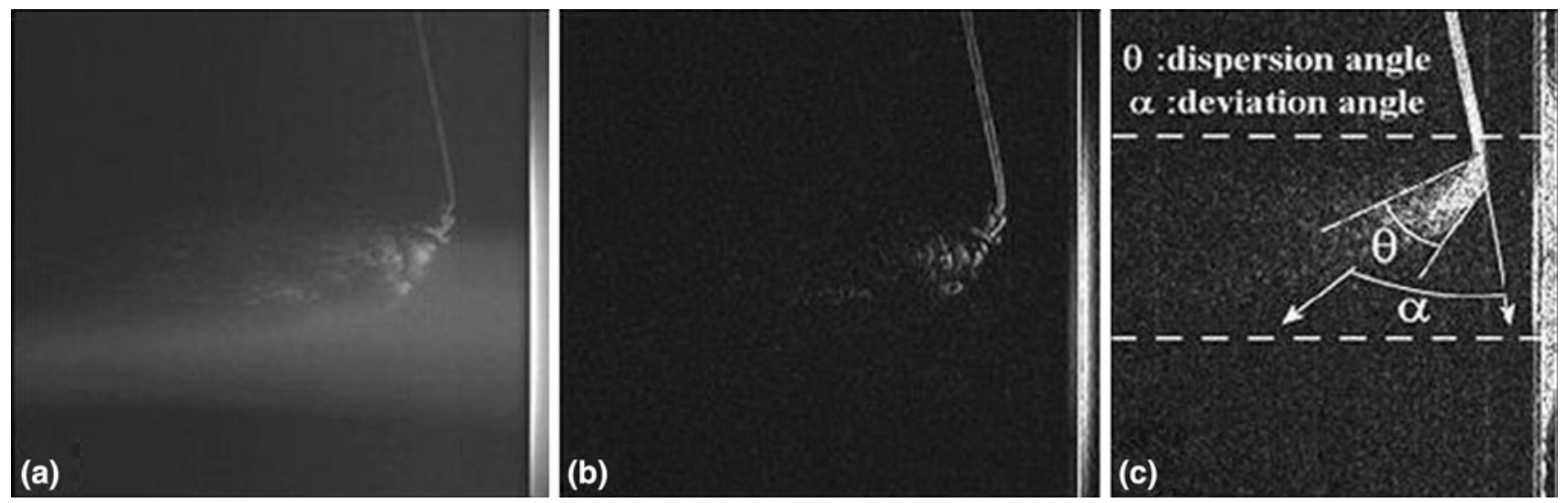

Fig. 17 Protocol of image processing: (a) original picture, (b) image obtained after filtering, and (c) result of the sum of several images treated (Ref 82)

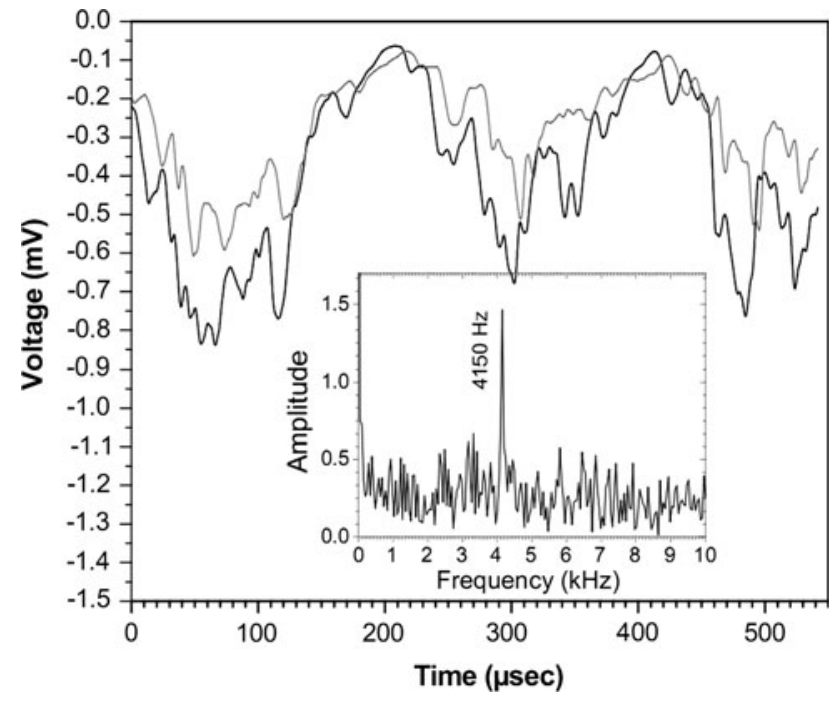

Fig. 18 Accuraspray signal and FFT in an Ar- $\mathrm{H}_{2}$ plasma produced with a MB-F4 torch in which are injected radially drops of $\mathrm{Al}_{2} \mathrm{O}_{3}$ suspension with 10 wt. $\%$ of powder (particle size: $27-43 \mathrm{~nm})($ Ref 83)

At last, it must be underlined that Obeste-Berghaus et al. (Ref 74) have evaluated, using the Accuracy ${ }^{\circledR}$ set-up of Tecnar, the ensemble velocity and temperature of the solid particles after their heating by the plasma jet once the suspension droplets have been evaporated. The measurement volume was centered in the spray plume at the location of the substrate during deposition. Because the small size of the particles prevents individual in-flight particle detection, an ensemble particle diagnostic system, which senses the fluctuations of the total emitted radiation in the field of view, is deemed necessary (Ref 83). A typical signal obtained with a conventional spray torch (Ref 28) is shown in Fig. 18. The Fourier transform signal at $4150 \mathrm{~Hz}$ coincides with the torch voltage oscillations and Accuraspray signals follow this fluctuation, demonstrating that the small particles follow the gas flow.
For example, with the MB-F4 torch working with $600 \mathrm{~A}$, $35 \mathrm{slm} \mathrm{Ar}, 10 \mathrm{slm} \mathrm{H}_{2}$ alumina particles mean velocity is $300 \mathrm{~m} / \mathrm{s}$ while their mean temperature is $2575^{\circ} \mathrm{C}(\operatorname{Ref} 28)$. With the Mettech Axial III torch (Ref 83) working with $200 \mathrm{~A}(83.2 \mathrm{~kW})$ and $245 \mathrm{slm}$ of $\operatorname{Ar}(75 \%), \mathrm{N}_{2}(10 \%)$ and $\mathrm{H}_{2}(15 \%)$ and particles of about the same size (29-68 nm) as those sprayed with the MB-F4 torch, the velocity reaches $574 \mathrm{~m} / \mathrm{s}$ with a temperature of $2520{ }^{\circ} \mathrm{C}$.

\subsection{Are Such Measurements Sufficient to Monitor Coating Properties?}

Considering such measurements two questions arise: Are they sufficient to determine what will be coating properties (Ref 84), and, if not, what is their usefulness?

\subsubsection{Conventional Processes.}

- As in these processes, particles at impact must be fully melted or close to their melting point, are the in-flight particle temperatures measurement sufficiently precise? First, the absolute temperature measurement is not very precise; errors in absolute temperature can approach $20 \%$ in some cases (see Ref 10-12 and Sect 2.1). Moreover, the mean temperature value is not very informative, a value over the melting temperature $T_{\mathrm{m}}$ does not necessarily means that all particles are fully melted upon impact. Reciprocally a mean temperature below $T_{\mathrm{m}}$ does not mean that all particles are un-melted. The interpretation of coating properties is by far easier with particle temperatures distribution than only mean values or ensemble measurement. That is why authors have proposed (Ref 7,85) instead of temperature non-dimensional and/or normalized parameters such as melting index and particle Reynolds' number as more appropriate descriptions of the particle state at impact.

- Coating properties are strongly linked to each particle flattening, solidification and resulting splat formation controlling the real contact splat-substrate or splatpreviously deposited layers. That is why during the last decade many works have been devoted to splat 
formation. These works were performed on smooth surfaces because of the low field depth of the microscope objectives that must be used to visualize them, see Ref 86 and the reviews (Ref 87, 88). Results of these studies underline the drastic importance of the substrate preheating over a so-called transition temperature $T_{\mathrm{t}}$. Over $T_{\mathrm{t}}$, on the one hand, adsorbates and condensates at the substrate surface are desorbed and, on the other hand, the oxide layer at the surface of metallic substrates is modified. Besides the modifications of thickness and composition, that of roughness, characterized by its skewness SK at the nanometer scale, may result, in certain cases, in a better-wet ability of the flattening droplet, also improving its contact with the substrate. To summarize, the quality of the contact splat-substrate is drastically improved when preheating the substrate over $T_{\mathrm{t}}$, parameter that is not controlled by particle parameters in-flight. Correspondingly, the coating adhesion on roughened substrates, with $R_{\mathrm{a}}$ in the few micrometers range, can be increased by a factor of 3 to 4 when they are sprayed after being preheated over $T_{\mathrm{t}}$ (Ref 87 ). Of course, preheating is generally performed with the spray torch. As most coatings are sprayed on metallic surfaces, it becomes very important to control the preheating time, rate, and temperature in order to monitor the formation of the oxide layer at the substrate surface (its composition and thickness). This is particularly true for certain metals very sensitive to oxidation such as for example low carbon steel (Ref 88).

- Besides the oxide formation, the control of the substrate and coating surface temperature before during and after spraying is very important to avoid temperature gradients within coating during its formation, especially when spraying materials with low thermal conductivity (below about $20 \mathrm{~W} \cdot \mathrm{m}^{-1} \cdot \mathrm{K}^{-1}$ ). The temperature distribution within the coating during the spray process influences strongly the residual stress distribution after coating and substrate cooling (Ref 89).

- The particle oxidation in-flight is also very important for coating properties. When spraying with d.c. plasma or HVOF or HVAF or wire arc guns, besides the oxidation by diffusion, a convective movement within molten particles can be induced by the hot gases flow. It produces a very strong oxidation (Ref 86) (up to 5 times that resulting from diffusion), because convection renews continuously the fresh metal at the particle surface while the oxide formed and/or the oxygen is entrained inside the particle (Ref 86, 90-92). This oxidation phenomenon cannot be detected by particles in-flight measurements.

- The spray pattern is also crucial through the number of passes, the scanning step, the relative speed spray gun-substrate, the spray distance, and the spray angle (Ref 93). These parameters are very important for the control of the coating mean temperature during spraying and the sticking at the surface of each pass of the poorly treated particles traveling in the jet fringes (especially the hot smaller ones).
2.4.2 Cold Spray. The development of the cold spray technique being more recent only a few papers were presented about the use of sensors to measure in-flight particle parameters. In this process, as particles are cold (or at least not hot enough to emit sufficient light to be detected by conventional sensors used in thermal spray processes), only velocity measurements are performed (Ref 62-65, 94). These velocity measurements have been mainly used to characterize the particle critical velocity, which also requires measuring the deposition efficiency. According to the few results published, there is no clear link established between particle velocities (over the critical velocity) and coating properties. For example, Raletz (Ref 95) has sprayed with helium nickel particles $(32-10 \mu \mathrm{m})$, for which the deposition efficiency was over $4 \%$ for a mean velocity of $504 \mathrm{~m} \cdot \mathrm{s}^{-1}$. He has shown that, for the same coating thickness, the coatings porosity was, in the measurement precision range, about $2 \%$, whatever may be the particles mean impact velocity for values varying between 540 and $780 \mathrm{~m} \cdot \mathrm{s}^{-1}$.

\section{Other Sensors or Measurement Devices}

According to the previous section, other parameters linked to coating generation, independently of the in-flight parameters, must be considered.

\subsection{Splat Formation}

During the last decade, splat formation measurements have allowed drastic strides in our understanding of coatings formation. Thus, even if sensors are not really used for such measurements it seems important to present them succinctly.

3.1.1 Case of Molten or Semi-Molten Particles. The coating adhesion-cohesion, as well as its thermomechanical properties, depend strongly upon the particle flattening and the corresponding splat formation; see the review papers ( $\operatorname{Ref} 87,88)$. In the eighties and at the beginning of the nineties, splats study was limited to some sort of zoological classification with no systematic study of the effects of the spray conditions and substrate state (Ref 96). At the end of the eighties, sophisticated fast pyrometers were developed for studying the flattening particle temperature evolution (see, e.g., Ref 97, 98). However, the signal interpretation was far to be easy without following simultaneously the evolution of the splat shape. Unfortunately, the flattening time being in the $\mu$ s range, and the fastest camera available working with one image/ $\mu$ s, it was not possible to follow the flattening particle shape evolution (Ref 88). That is why shadowing technique (Ref 99) of the splat flattening on a glass substrate was developed. Considering particles with the same impact parameters, photographs of different particles were taken at different flattening times (Ref 98, 99). Such measurements have confirmed phenomena followed with millimetre-sized drops, whose flattening time is in the 
ms range and for which fast cameras ( 5000 images/s $)$ can be used (Ref 87,88 ). They have also demonstrated the importance of substrate preheating over the transition temperature to achieve disk-shaped splats. Dhiman et al. (Ref 100) have given an excellent review of how the splat shape depends on the substrate conditions and particle impact parameters.

3.1.2 Case of Un-Melted Particles. As for conventional thermal spray, the understanding of splat formation is a key issue to improve coating properties. Unfortunately, it is more difficult than with molten or semi-molten particles. That is due to the fact that cold particles do not emit enough light to be observed directly and the impacting velocities, generally over $500 \mathrm{~m} \cdot \mathrm{s}^{-1}$, allow even less to follow the impact with fast cameras. For cold spray process, only solid particles impact (resulting in "solid" splats), while with HVAF or high power HVOF processes also molten particles (resulting in "splash" and "disc" splats) and semi-molten ones (resulting in "slushy/ broken/semi-molten" splats) are observed (Ref 101). Thus, actually, the only way to study solid splat formation is to observe them, once deposited, with an optical microscope, a focused ion beam (FIB), cross-sectional scanning electron microscopy (SEM), and cross-sectional transmission electron microscopy (TEM). It means that for solid splats the situation is the same as that occurring at the end of the eighties for splats resulting from molten or semi-molten particles, except that now the impact velocity can be measured and linked to the splat shape. Such studies have allowed determining cratering of the substrate, splats formed and material ejection according to the influence of particle sizes, spray conditions (particle velocity and temperature at impact) and substrate hardness and temperature (Ref 63, 102-109).
For example, Fukumoto et al. (Ref 108) have studied the effect of AISI304 stainless steel substrate temperature on the deposition behavior of $\mathrm{Cu}$ particles cold sprayed with helium. The gas temperature was kept as low as possible to eliminate the effect of particle heating. It is clear from Fig. 19 that the deposition ability increases and the number of craters decreases remarkably with the increase in substrate temperature.

Such measurements have allowed determining the induction time in Cold Spray. When starting with a smooth surface, particles are not attaching at first and they rebound, thus cleaning and deforming the surface. At a time $t_{\mathrm{i}}$ (approximately a few tens of seconds) called induction time, particles begin to attach, provided their velocity is higher than a critical velocity, $v_{\mathrm{c}}$. This attachment occurs in an avalanche-like manner, rapidly forming the coating. This is illustrated in Fig. 20 from Klinkov and Kosarev (Ref 110).

\subsection{Hot Gas Heat Flux}

Hot gases and the impacting molten or semi-molten particles heat the substrate and coating, during spraying. The heat flux, due to the hot gas expansion downstream of the nozzle exit, decreases rather rapidly with the spray distance (almost exponentially). However, when spraying solutions or suspensions at very short distances (30-40 mm with plasma jets and $60-90 \mathrm{~mm}$ with HVOF jets), heat fluxes can reach a few tens of MW requiring low residence time of the torch at the same location and efficient cooling systems, generally with gas jets. The heat flux measurement requires, for axisymmetric jets, calorimetric measurements (Ref 111-113). Commercial calorimeters exist, but generally for heat fluxes below $5 \mathrm{MW} \cdot \mathrm{m}^{-2}$. For higher
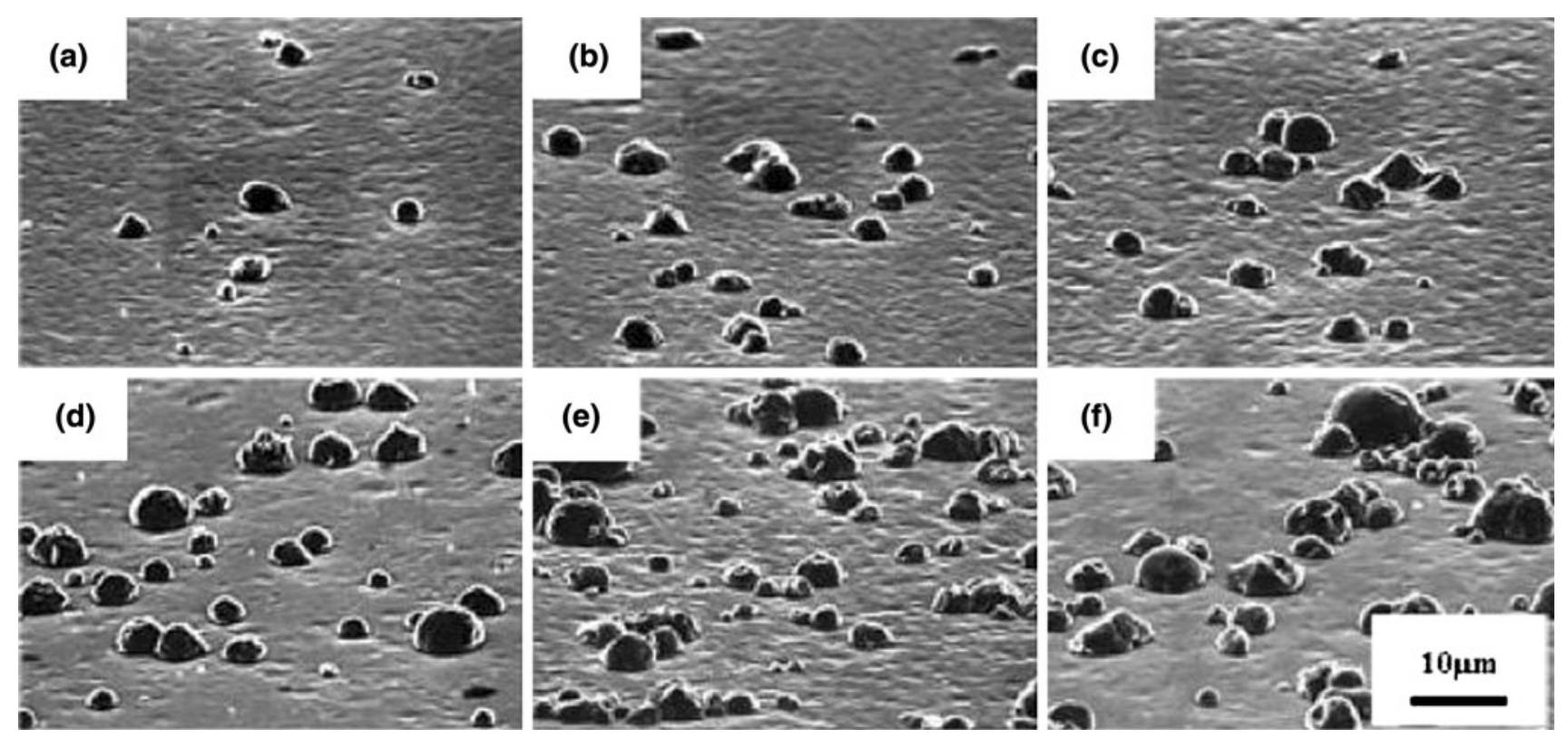

Fig. 19 Morphologies of collected particles (particle size: $5 \mu \mathrm{m}$, AISI 304 substrate). (a) Gas pressure: 0.4 MPa, gas temperature: 523 K; (b) $0.5 \mathrm{MPa}, 523 \mathrm{~K}$; (c) $0.6 \mathrm{MPa}, 523 \mathrm{~K}$; (d) $0.4 \mathrm{MPa}, 923 \mathrm{~K}$; (e) $0.5 \mathrm{MPa}, 923 \mathrm{~K}$; (f) $0.6 \mathrm{MPa}, 923 \mathrm{~K}$ (Ref 108) 


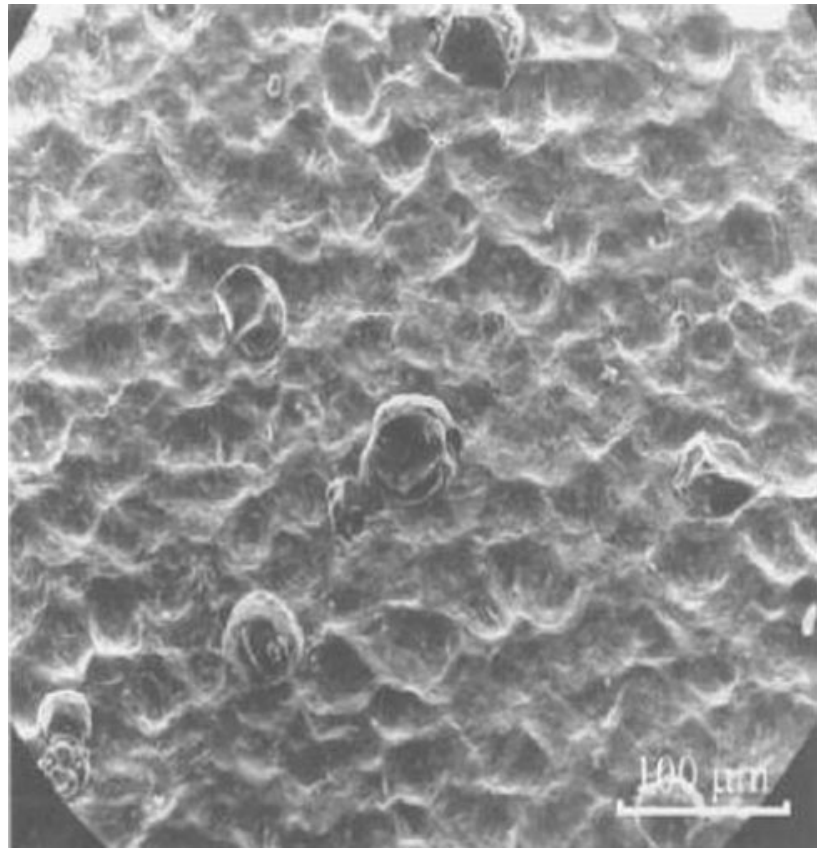

Fig. 20 Copper substrate surface after a $25 \mathrm{~s}$ delay in a twophase jet. Impact of aluminum particles $(30 \mu \mathrm{m})$ onto a copper substrate (Ref 110)

fluxes the central part of the calorimeter with a surface between a few tens and a few hundreds of $\mathrm{mm}^{2}$ is highpressure (up to $3 \mathrm{MPa}$ ) water-cooled, and it is surrounded by a ring calorimeter also water-cooled, the water connections being such that no heat flux is exchanged between both calorimeters. One of the difficulties is the interpretation of results, the central calorimeter and especially the ring one modifying the free hot gases flow. Moreover, at short distances $(<50 \mathrm{~mm})$, where most calorimeters give up, a copper target crossing rapidly the jet $(30 \mathrm{~m} / \mathrm{s})$ allows measuring the total heat flux received from the plasma jet, giving a good approximation of the heat flux (Ref 114).

\subsection{Substrate Temperature Control}

It has been emphasized that the monitoring of coating temperature before, during, and after spraying is as important for the coating quality, reliability, and reproducibility as monitoring particle velocities, temperatures, and trajectories (Ref 3,11,29). Thus, many efforts have been devoted to coating temperature monitoring during the spray process by different means:

- Infra red (IR) pyrometers (Ref 115-117), wavelengths over $6 \mu \mathrm{m}$ being less sensitive to radiation of the plasma or hot gases as well as hot particles (Ref 115).

- IR thermography (Ref 118-120).

- Embedded and fast response micro-thermocouples in metallic substrate (Ref 121, 122) with the still unresolved problem of the lack of good contact between substrate and coating, especially for low conductivity sprayed materials.

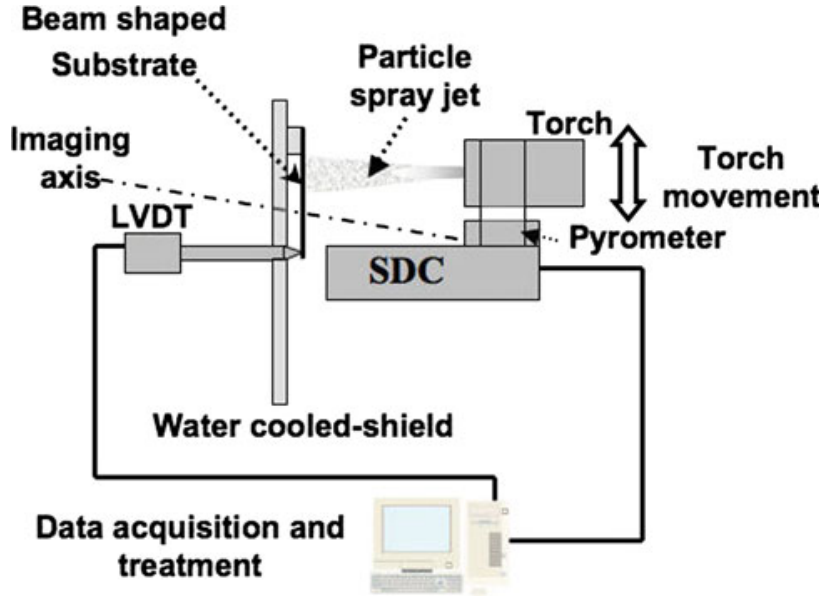

Fig. 21 Set-up developed with the Spray and Deposit Control to follow continuously the beam-shaped substrate bending before, during, and after spraying while controlling the substrate and coating temperature (Ref 127)

At last, it must be recalled that the coating temperature depends on the pass thickness, especially for low thermal conductivity (below about $20 \mathrm{~W} \cdot \mathrm{m}^{-1} \cdot \mathrm{K}^{-1}$ ) sprayed materials, the spray pattern, the spray distance, and the cooling systems used as well as their positioning.

\subsection{Stress Development During Spraying}

To determine the stress formation in situ during spraying, the curvature of a beam, made of the substrate metal, is continuously recorded during the spray process (preheating, coating, and cooling) in parallel with the substrate and coating temperature.

The first works on this technique were initiated by Kuroda and Clyne (Ref 123-126) at the end of the eighties and the beginning of the nineties and then developed by other authors (Ref 112, 127-132). One of the set up used (Ref 127, 128) is represented in Fig. 21. The beam-shaped substrate is fixed at one of its extremity on a water-cooled shield and its curvature is continuously recorded with a sensor (LVDT). Meanwhile, the pyrometer of the spray and deposit control (SDC) set-up measures continuously the substrate and then the coating surface temperature. Of course, in parallel the particle trajectories are monitored with the SDC.

Typical signals observed during plasma spraying are presented in Fig. 22. The fluctuating curve represents the surface temperature evolution. The strong variations are due to the torch pattern during spraying. As the detector is fixed on the torch sometimes it 'sees' the substrate or coating hot surfaces and sometimes the surrounding of the set-up (the water-cooled shield). The bending curve with a positive steep slope corresponds to the quenching stress generated during the spray process while that with a decreasing shape corresponds to the expansion mismatch stress developing after spraying when substrate and coating cool down. 


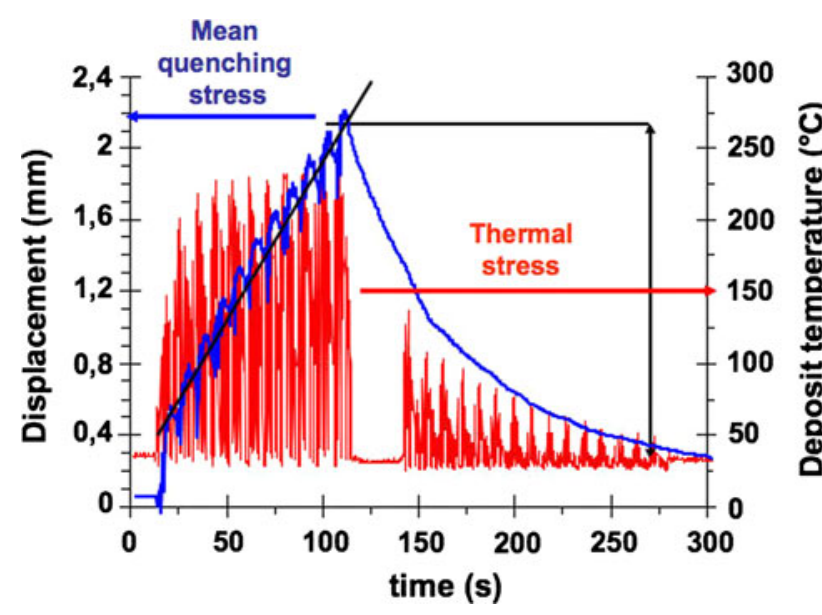

Fig. 22 Surface temperatures of substrate and coating evolution during the spray process as well as that of the beam bending (Ref 127)

\subsection{Coating Thickness Measurement}

Coating thickness is one of the most important parameters to monitor and control. Unfortunately, most measurements are generally destructive (after spraying) and time-consuming. A novel approach has been recently developed (Ref 133) enabling on-line, real-time and noncontact measurement of individual spray pass thickness during deposition.

It is based on simple optical triangulation to detect the smooth step profile of a pass over the immediately adjacent uncoated (or previously coated) surface. The strategy consists in recording the profile of the coating at the frontier between the new layer and the previous one using a laser line projected across the pass edge and captured with CCD camera. Measurements are independent of coating/substrate nature, the surface roughness or the thermal expansion of the coated part. For on-line tests on cylinders the precision is about $5 \mu \mathrm{m}$.

\section{Other Possible Measurements}

To achieve a better understanding of the momentum and heat transfer between hot gases and particles injected, the knowledge of the gas temperature and velocity is helpful. It could also be interesting to determine how particles evaporate. Many measurements of this type have been performed in laboratories for plasma jets, where lines and continuum emission are very important and can be used for such measurements.

\subsection{Plasma Jet Temperature}

Many studies were devoted to spectroscopic measurements of plasma jets with conventional torch configurations (Ref 10,11) (concentric anode-cathode) allowing the observation under a single angle followed by Abel's

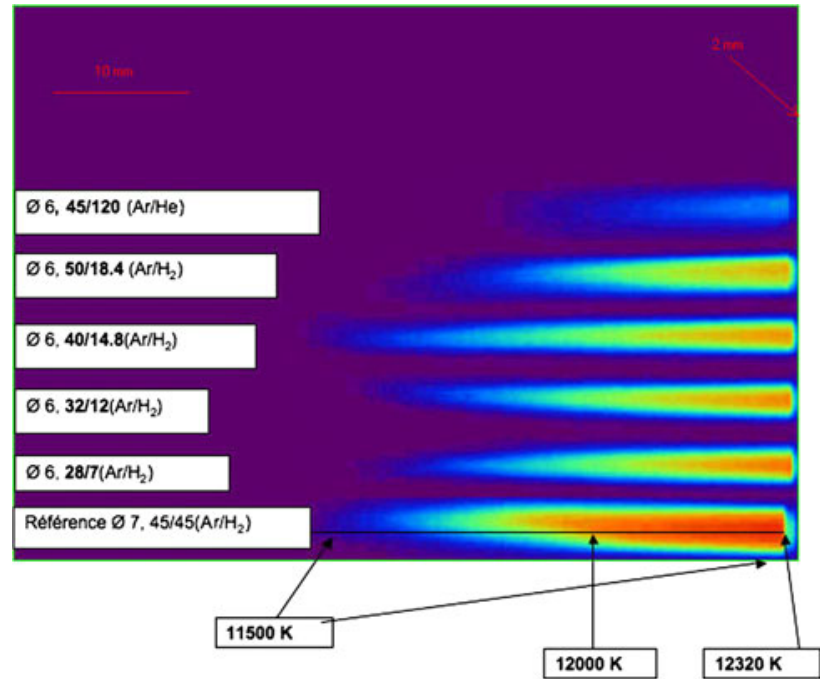

Fig. 23 Images of different plasma jets obtained with a CCD camera filtered between 806 and $816 \mathrm{~nm}$ (corresponding to ArI line) and for different working conditions with argon as primary gas (Ref 133)

inversion. The problem becomes more complex with torches such as Triplex ${ }^{\circledR}$ from Sulzer-Metco resulting in fact in three plasma jets with an axis of symmetry. In such cases, only plasma computer tomography can be used as explained by Landes (Ref 24 ) provided the stability of the plasma jets is good.

A very simple system can be used to check rapidly if the plasma jet produced later on is identical to that used previously with the same working conditions. It consists in using a simple CCD camera (time averaged images of $0.04 \mathrm{~s})$ with a filter corresponding for example to argon lines (806-816 nm) (Ref 21). Few examples of different plasma jets with argon as primary gas are presented in Fig. 23. With the help of emission spectroscopy, images can be roughly calibrated. However, the main interest of such images is to compare the length and diameter of the new jet with the image recorded previously in the same working conditions.

\subsection{Particle Vaporization}

Two possibilities exist but, to our knowledge, only in laboratory conditions:

- Emission spectroscopy (analysis similar to chemical analysis in ICP plasma). As the sprayed particles are not completely vaporized, a few assumptions are mandatory: constant gas velocity and laminar flow within the analyzed volume, LTE prevailing, heat conduction in axial direction negligible (Ref 134).

- Absorption spectroscopy to determine the ground state populations of atoms and ions spectral lines being absorbed proportionally to the number of absorbing atoms (Ref 135-137). 


\section{Examples of Sensors Used}

The ideal condition would be a reliable link between coating properties and parameters of the different sensors: those measuring the in-flight particle parameters and those characterizing the coating during its formation (temperature, residual stress...). In this case, an on-line control could be achieved. Unfortunately, it is still far to be the case, the link between the different sensor parameters and coating properties being still an enigma. That is why in the following will be presented successively:

- the influence of the spray parameters on the in-flight particle parameters and

- the different attempts to monitor on-line certain coating properties with sensors.

\subsection{Particles In-Flight: Influence of Spray Parameters}

5.1.1 Hot Particles. Many works have been devoted to characterize the influence of the spray conditions on the in-flight particle parameters. Researchers have especially considered the effects of these conditions, and corresponding particle parameters, on deposition efficiency and some coating properties such as porosity, hardness... Comparison of different torches has also been done.

Plasma Jets. For example, Bisson et al. (Ref 138), using DPV-2000, have studied the influence of the hydrogen percentage and injector geometries on YSZ particles sprayed with nitrogen/hydrogen using a Sulzer Metco $9 \mathrm{MB}$ gun. Deposition efficiencies and coating porosities were compared for different spray gun conditions yielding a similar input power. It has been shown that the same input power obtained by increasing the arc current or by increasing the hydrogen flow rate resulted in different coating properties. Marple et al. (Ref 6), using Accuraspray, have compared YSZ coatings sprayed with $\mathrm{Ar}-\mathrm{H}_{2}$ and $\mathrm{N}_{2}-\mathrm{H}_{2}$ plasmas. With $\mathrm{N}_{2} / \mathrm{H}_{2}$ plasma gas mixture, higher in-fight particle temperatures and lower particle velocities were produced as compared with $\mathrm{Ar}-\mathrm{H}_{2}$ plasmas. Coatings had similar hardness values; however, the Young's modulus and thermal diffusivity following heat treatment were lower. Planche et al. (Ref 139) have studied, with a DPV-2000, alumina particles in-flight and compared measurements with calculations. The calculated particle velocities and temperatures were in good agreement with the experimental results: discrepancies being less than $10 \%$. Tekmen et al. (Ref 140), using Accuraspray-g3, have optimized the spraying of cast iron to control the graphite content. A wide range of in-flight particle temperature and velocity values with constant graphite carbon content was determined.

Zhang et al. (Ref 141) have studied the influence of particle parameters onto the ionic conduction of YPSZ. Teckmen et al. (Ref 142,143) have linked the spray conditions to particle parameters and alumina formation

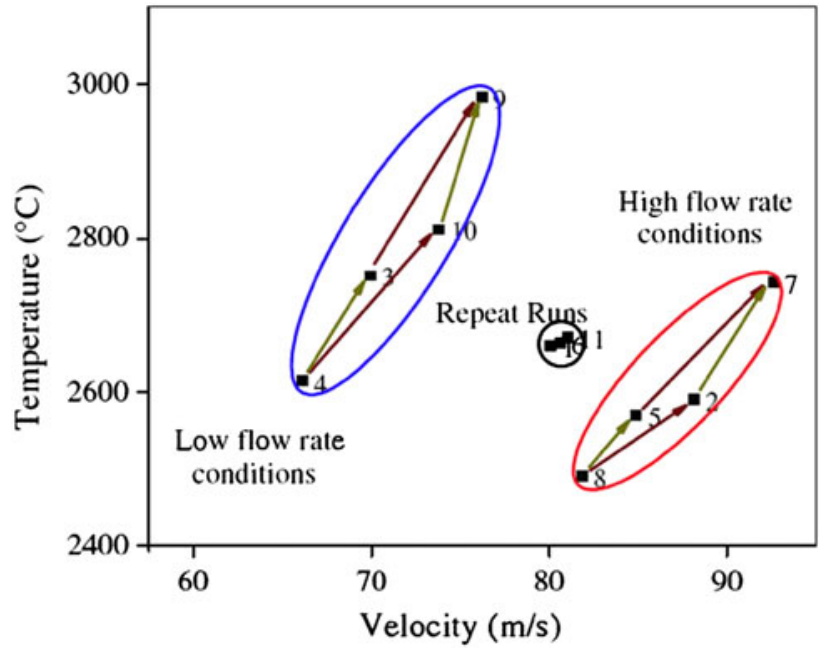

Fig. 24 First-order process map for APS of CoNiCrAlY material. Results identify the particle state response for various torch operating conditions as well as the control vectors identifying the influence of arc current and secondary gas flow rate (Ref 7 )

when spraying Al-12Si particles. Yin et al. (Ref 144) have studied the influence of alumina particle sizes on their in-flight parameters and bonding. Wang et al. (Ref 145) have shown the possibility to tailor alumina-zirconia coatings with two powder injection ports. Fang et al. (Ref 146) have studied the influence of spray conditions on YPSZ particle parameters...

Such measurements allow drawing what Sampath et al. (Ref 7) call first-order process maps as illustrated in Fig. 24. In this figure are identified the particles (CoNiCrAlY, 38-57 $\mu \mathrm{m}$ ) state response for various torch operating conditions as well as the control vectors identifying the influence of the secondary gas flow and torch current in terms of particle temperatures and velocities. These quantitative vectors can be used as feed back control.

From such measurements, Srinivasan et al. (Ref 5) estimate that there exist at least a few control protocols to monitor the particle state (predominantly temperature and velocity) with judicious choice of critical parameters. They have controlled the particle state by varying the critical torch parameters (primary gas flow and arc current) in a narrow range using yttria (8 wt.\%)-zirconia particles with angular shape. The particle state resulting from averaged individual particle measurements (DPV2000 ) is surprisingly stable with variability in temperature $<1 \%$ and variability in velocity of $<4 \%$. Ensemble approaches yield a somewhat higher variability $(5 \%$ in temperature). Despite this, the variability in basic coating attributes, such as thickness and weight, is surprisingly large. Applying a much simpler control strategy to only monitor the particles injection and hence their trajectories results in reduced variability in coating attributes. This is in good agreement with previous measurements showing that when particle trajectories were not too far from the optimum one about the same temperatures and velocities were obtained (Ref 30$)$. 
Such measurements allow also following electrodes erosion. Leblanc and Moreau (Ref 9) ran an experiment that lasted for $55 \mathrm{~h}$ of spraying using a model F4-MB plasma gun. Due to voltage lowering, the state of the sprayed particles significantly changed with spraying time when the arc current or the gun power was kept constant. Maintaining the plasma net energy to a constant value, by increasing the arc current and not the hydrogen percentage (see next section), was a good means to indirectly control this spray process.

The effect of the voltage fluctuations on the in-flight particles is not straightforward because it depends both on the plasma forming gases and the torch design. Temperature and velocity fluctuations can be very important as shown in Sect 2.1.6 and Fig. 9. Moreover, such fluctuations have a strong effect on the coating microstructures as demonstrated by Moreau (Ref 147) for $\mathrm{Ar}-\mathrm{H}_{2}$ plasmas. They sprayed with the same torch, working with argon (35 $\mathrm{slm})$ as primary gas, alumina particles $(22-45 \mu \mathrm{m})$ with either low current (300 A) and high hydrogen flow rate (10 slm) corresponding to large power fluctuations, or with high current (700 A) and low hydrogen flow rate $(3 \mathrm{slm})$ resulting in low power fluctuations. The corresponding coatings are presented in Fig. 25.

With the high power fluctuations, the porosity $(P)$ is about $7 \%$ with 1000 unmelted particles $/ \mathrm{mm}^{2}$ and a deposition efficiency (DE) of $48 \%$, while with the low power fluctuation $P=4.5 \%, \mathrm{DE}=73 \%$ and only about 350 unmelted particles $/ \mathrm{mm}^{2}$ are observed. This is mainly due to the plasma jet momentum density $\left(\rho v^{2}\right)$ fluctuation modifying continuously particle trajectories.

HVOF Spraying. Works were devoted to spraying conventional particles of $\mathrm{TiO}_{2}$ (Ref 148, 149), $\mathrm{Al}_{2} \mathrm{O}_{3}$ (Ref 149, 150), and Inconel (Ref 151). These studies
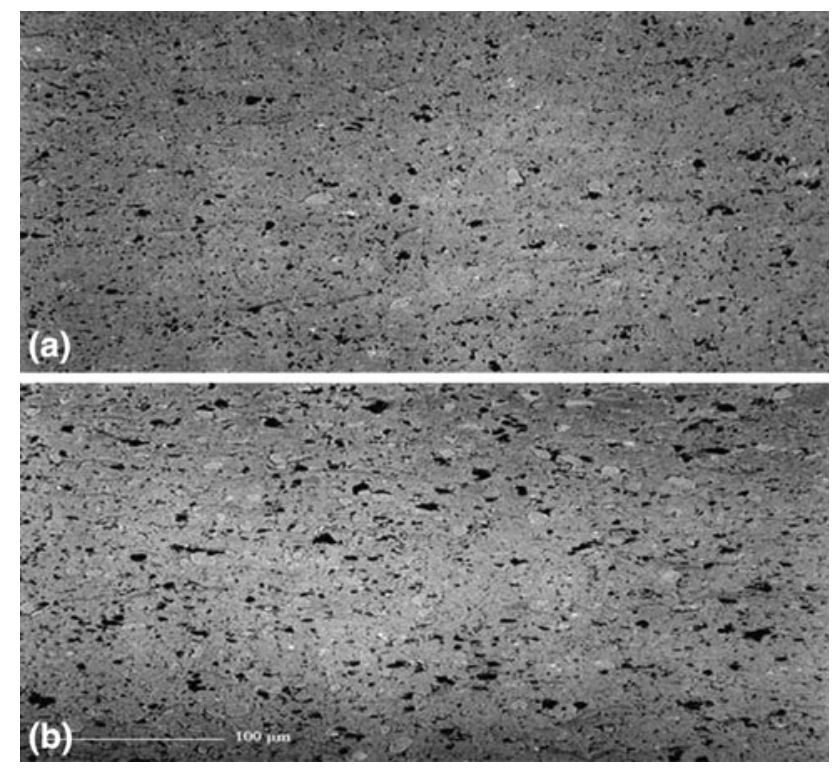

Fig. 25 Alumina coatings $(22-45 \mu \mathrm{m}$ particles) sprayed with Ar- $\mathrm{H}_{2}$ mixtures. (a) With a high-power fluctuations $(10-30 \mathrm{~kW})$ and (b) low-power fluctuation (27-35 kW) (Ref 147) emphasized the importance of impacting particle temperatures on the deposition efficiency and some coating properties.

Comparison of HVOF Guns and Axial III Plasma Torch. Three oxygen-fuel guns (JP5000, JP5000 ST, Diamond jet DJ2700) and Axial III plasma gun were compared to spray WC-10Co-4Cr powder (Ref 20). The plasma Axial III provided the highest particle temperatures (between 2000$2600{ }^{\circ} \mathrm{C}$ ) depending on the spray conditions, while the JP5000 imparted the highest velocities $(550-700 \mathrm{~m} / \mathrm{s})$. The ST version of JP5000 has provided the same velocity but with lower temperature (around $1500{ }^{\circ} \mathrm{C}$ ). The DJ2700 sprayed particles with temperatures and velocities between those of Axial III and JP5000. Best results were achieved with the lowest particles mean temperature and the highest velocity.

Agglomerated Nanometre-Sized Particles. The use of sensors controlling particle temperatures is particularly important when spraying agglomerated nanometre-sized particles (Ref 152). It allows engineering the amount and distribution of dense and porous nano-zones (formation of a bi-modal structure: micrometer and nanometre zones). The formation of nano-zones depends on the control of the heat propagation within oxide particles (Ref 153). Typical examples are those obtained when spraying $\mathrm{Al}_{2} \mathrm{O}_{3}-\mathrm{TiO}_{2}$ and $\mathrm{TiO}_{2}$ particles both by APS and HVOF (Ref 154, 155). Authors showed that coatings obtained with the nanostructure materials presented a higher wear resistance than coatings obtained with conventional particles. HVOF-spayed nanostructure $\mathrm{TiO}_{2}$ coatings exhibited higher wear resistance when compared to APS sprayed ones. This better resistance to wear is provided by nano-zones imbedded in the dense and uniform coating microstructure acting as crack arresters and thereby increasing the coating toughness. Lima and Marple (Ref 155) have compared temperatures and velocities of conventional $\mathrm{Al}_{2} \mathrm{O}_{3}-\mathrm{TiO}_{2}$ particles plasma sprayed with those of nanostructure $\mathrm{TiO}_{2}$ particles HVOF sprayed. Temperatures of conventional particles are higher while their velocities are lower, as illustrated in Fig. 26. Thus, more semi-molten particles are kept with HVOF spraying. The molten part of the feedstock has fully or almost fully penetrated into the porous core of the particle during flight and/or impact on the substrate. It resulted in dense finely dispersed nano-zones within coating. When spraying nanostructured YSZ for thermal barriers, it has been shown that the best results were obtained with particle mean temperatures of about $60-100{ }^{\circ} \mathrm{C}$ below the melting point (Ref 156).

HVOF has been used to spray agglomerated nanostructured particles: $\mathrm{TiO}_{2}$ ones (Ref 157, 158) and WC-Co ones (Ref 159). In the latter case, one powder, called multimodal, has been engineered to have a bimodal WC grain size distribution. It consisted of a 50-to-50 mixture of two size fractions: coarse grains of 1 to $3 \mu \mathrm{m}$ and fine grains of 30 to $50 \mathrm{~nm}$. For all WC-Co powders, a process window was defined with respect to particle temperature

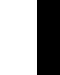




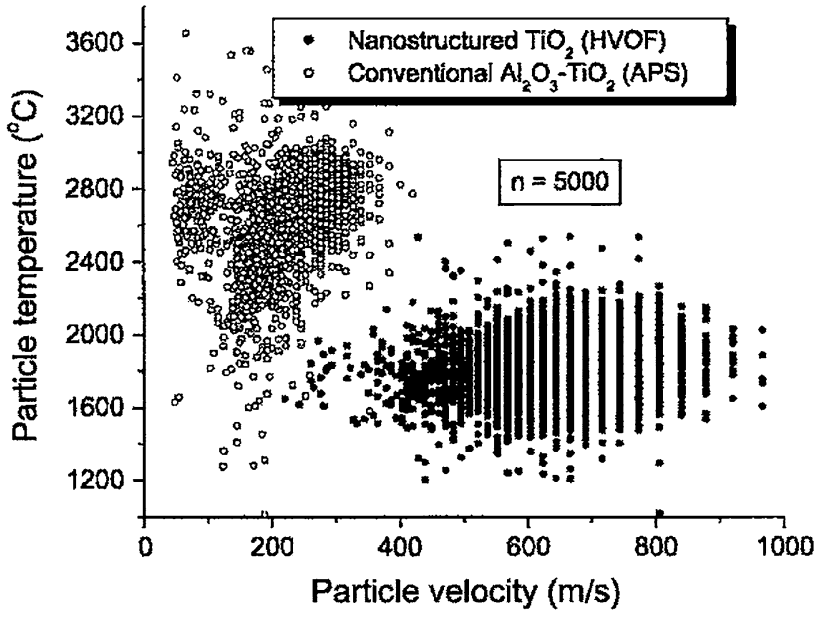

Fig. 26 Distribution of particle temperatures and velocities in the spray jets for the nanostructured titania and conventional alumina-titania feedstock particles (Ref 155)

to achieve the highest resistance to dry abrasion. The multimodal coatings tend to have a higher hardness than conventional coatings; however, in terms of abrasion resistance, there is little difference between the bestperforming multimodal and conventional coatings. For the nanostructured $\mathrm{TiO}_{2}$ coatings (Ref 157), HVOF-sprayed, different spraying conditions were studied. It was shown that a linear dependence between particle temperatures and particle velocities existed when spraying this type of powder using HVOF-spraying. The higher the average particle temperature and velocity, the higher was the Vickers micro hardness number. Higher particle temperatures and velocities enhanced the inter-splat contact, thereby increasing the cohesive strength of the coating.

To conclude, adjusting, through the in-flight mean temperature measurements and the use of either plasmas or HVOF guns with different working conditions and the choice of the size distribution of nano-sized agglomerated particles, allows achieving dense or porous nano-zones (Ref 152). It results in coatings with different properties, from good wear resistance to abradable.

Wire Arc Spraying. DPV-2000 was used to differentiate particles produced by atomization of the molten metal either at the cathode or anode (Ref 160). The spray conditions influence on particle characteristics was studied (Ref 27) and experimental results compared with those of CFD study (Ref 161). The model was validated on the basis of comparisons between in-flight droplet velocity measurements performed using the DPV-2000 diagnostic tool.

A hybrid system consisting of a twin-wire arc where the high-velocity atomization gas produced by HVOF gun has also been studied (Ref 162). In this system, the particle velocities are significantly higher than those in a conventional wire arc, resulting in high-density coatings.

5.1.2 Suspension Spraying. According to the techniques described in Sect 2.3, the optimization of suspension

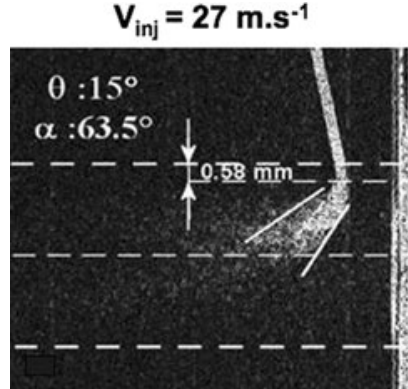

(a)

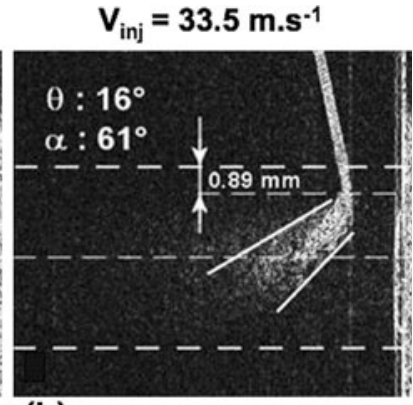

(b)
Fig. 27 Evolution of the suspension jet dispersion angle $\theta$ and deviation angle $\alpha$ of the liquid droplet clouds when injected in an Ar-He plasma jet (700 A, anode-nozzle i.d. $6 \mathrm{~mm}$, Ar $30 \mathrm{slm}, \mathrm{He}$ $30 \mathrm{slm}$ ) with a liquid jet velocity of (a) $27 \mathrm{~ms}^{-1}$ and (b) $33.5 \mathrm{~ms}^{-1}$ (Ref 69)

injection has been systematically studied. When injecting a liquid within a hot gas jet (Ref 67, 68), the latter first fragments the liquid, where vaporization occurs in times two to three orders of magnitude longer. Thus, contrary to solid particles spraying, the mass of the resulting droplets is continuously diminishing, the final droplet size being up to two orders of magnitude smaller than that of initial drops. It is thus necessary to increase drastically their initial velocity to keep the droplet momentums high enough for them to penetrate in the jet core. It means that the momentum density of initial drops or jet $\left(\rho_{\mathrm{L}} v_{\mathrm{L}}^{2}\right)$ must be very large compared to the plasma jet momentum $\left(\rho v^{2}\right)$. For example, suspension drops (in ethanol) $300 \mu \mathrm{m}$ in diameter must be injected with a velocity of at least $30 \mathrm{~m} \cdot \mathrm{s}^{-1}$ (corresponding to $\rho_{\mathrm{L}} v_{\mathrm{L}}^{2}=0.7 \mathrm{MPa}$ ) to achieve their good penetration within a $10000 \mathrm{~K} \mathrm{Ar}-25$ vol. $\% \mathrm{H}_{2}$ plasma jet flowing at $2000 \mathrm{~m} \cdot \mathrm{s}^{-1}$ corresponding to $\rho v^{2}=$ $0.03 \mathrm{MPa}$. In Fig. 27 is presented the laser illuminated plasma jet with the suspension mechanical injection. As it can be observed few fragmentations occur in the plasma jet fringes resulting in droplets that will be evaporated but with a poor heat treatment of the solid particles they contain. The Weber number characterize the fragmentation by a cold gas flow (which is not quite the case of a plasma jet!):

$$
W_{\mathrm{e}}=\frac{\rho \Delta U^{2} d_{\mathrm{L}}}{\sigma_{\mathrm{L}}}
$$

where $\rho$ is the plasma specific mass, $d_{\mathrm{L}}$ the liquid jet or drop diameter, $\sigma_{\mathrm{L}}$ the liquid surface tension and $\Delta U=v-$ $v_{\mathrm{L}}$ with $v$ the plasma jet velocity and $v_{\mathrm{L}}$ the liquid velocity. Figure 27 obtained by superposing and filtering (see Sect 2.3) about 10 images taken, in less than $1 \mathrm{~s}$, at the same transient voltage, shows how the suspension penetrates into the plasma jet core according to its initial velocity. With $v_{\mathrm{L}}=27 \mathrm{~m} \cdot \mathrm{s}^{-1}$ (Fig. 27a) fragmentation starts in the jet fringes after $580 \mu \mathrm{m}$ trajectory and the droplets cloud reaches the torch axis.

On the contrary with $v_{\mathrm{L}}=33 \mathrm{~m} \cdot \mathrm{s}^{-1}$, the fragmentation starts only after $890 \mu \mathrm{m}$ trajectory in the jet fringes and droplets penetrate deeper. Globally $\alpha$ and $\theta$ are only 

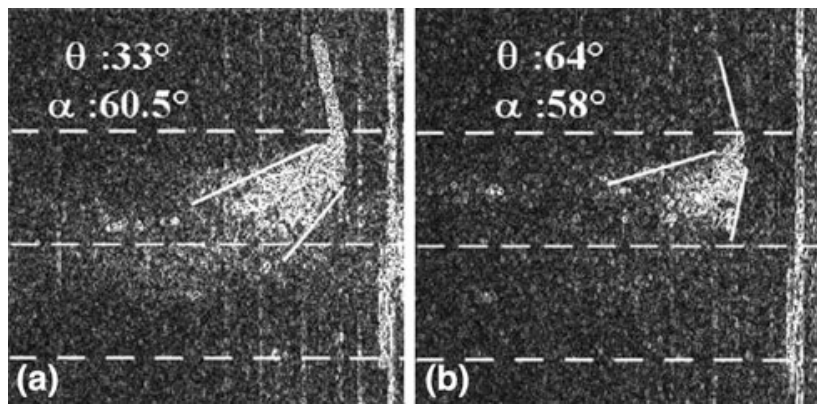

Fig. 28 Evolution of the suspension jet dispersion angle $\theta$ and deviation angle $\alpha$ of the liquid droplet clouds when injected in $\mathrm{Ar}-\mathrm{H}_{2}$ d.c. plasma jet (500 A, nozzle-anode i.d., $\mathrm{Ar} 45 \mathrm{slm}, \mathrm{H}_{2} 15$ $\mathrm{slm}$ ) for a liquid jet velocity $v_{\mathrm{L}}=26.6 \mathrm{~m} \cdot \mathrm{s}^{-1}$ : (a) at the maximum voltage: $80 \mathrm{~V}$ and (b) at the minimum voltage: $40 \mathrm{~V}$ (Ref 69)

slightly modified. Correlatively denser coatings are achieved with $v_{\mathrm{L}}=33.5 \mathrm{~m} \cdot \mathrm{s}^{-1}$. Figure 28 illustrates the influence of the plasma jet fluctuations on the suspension treatment. Compared to the stable Ar-He plasma, where voltage fluctuations $\Delta V$ are low $\left(\Delta V / V_{\mathrm{m}}=0.25\right.$ where $V_{\mathrm{m}}$ is the mean voltage), the $\mathrm{Ar}-\mathrm{H}_{2}$ jet is very instable with $\Delta V / V_{\mathrm{m}}=1$.

Figure 28(a) and (b) shows that the deviation angle of the liquid jet is not very sensitive to the voltage variations, while the dispersion angle $\theta$ at $80 \mathrm{~V}$ is almost half that obtained at $40 \mathrm{~V}$. Moreover, the suspension penetration in the plasma jet is rather poor. The coating porosity with the $\mathrm{Ar}-\mathrm{H}_{2}$ plasma is more than doubled compared to that obtained with the Ar-He plasma with the same suspension. Such visualizations, which require a few seconds, allow optimizing the suspension mechanical injection for different solvents, mass load of particles...

5.1.3 Cold Particles. As already mentioned (Ref 63), the substrate temperature (measured with a fast IR camera) and the impact velocity of particles (measured with DPV-2000) in cold spray play a key role in coating formation and adhesion. Over the critical velocity at constant gun temperature, the substrate surface temperature was varied using a substrate heater. For $\mathrm{Al}$ the deposition efficiency increased as the surface temperature increased. For $\mathrm{Zn}$ it was the opposite, the DE decreases and for $\mathrm{Sn}$ no significant change was observed. Using Spray Watch and measuring the deposition efficiency of $\mathrm{Cu}$ particles, Ning et al. (Ref 65) have shown that the irregular-shape particles presented higher in-flight velocity than the spherical-shape ones under the same spray conditions. Compared to spherical $\mathrm{Cu}$ particles, the critical velocity with irregular-shape ones was about $125 \mathrm{~m} / \mathrm{s}$ lower. Furthermore, the preheating treatment of feedstock powder decreased the critical velocity and increased the deposition efficiency of copper powder. That resulted from the decrease of micro hardness of particles during the vacuum annealing treatment at temperatures over $390{ }^{\circ} \mathrm{C}$. Similar results were obtained when comparing critical velocities (measured with DPV-2000) of non-spherical and spherical stainless steel 316L particles (Ref 163). However, if the non-spherical particles were faster, the critical velocity of both powders was almost the same and did not depend on their micro-hardness. Irissou et al. (Ref 62) have investigated coating build-up mechanisms and properties of coldsprayed aluminum-alumina cermets. They used two spherical aluminum powders having respective average diameters of 36 and $81 \mu \mathrm{m}$ and they measured particle velocities with DPV-2000. They have shown that the Al powder having the larger particle size distribution has a volume fraction of particle having a velocity higher than the critical velocity significantly less than that of the smaller particle of Al powder. Its deposition efficiency was consequently lower. However, coatings with the starting powder based on the larger $\mathrm{Al}$ particles were systematically harder than coatings made with the smaller size $\mathrm{Al}$ powder mixtures. This was likely due to the more important peening effect of the large particles due to their higher kinetic energy.

$\mathrm{Li}$ et al. (Ref 64) have compared the measured $\mathrm{Cu}$ particle velocities with the calculated results using a twodimensional axisymmetric model, developed previously, and found a good agreement between both. Jodoin et al. (Ref 61) made similar comparisons when spraying nickel particles.

\subsection{Coating Properties Monitoring}

As presented in the previous section, sensors have been mainly used to find either relationships existing between in-flight parameters and spray conditions, or compare calculations with measurements, or determine the effect of particle temperatures and/or velocities on a specific property of the coating. Their main goals were to optimize spray parameters, improve the reliability, and the reproducibility of coatings, compensate the drift of these in-flight parameters with the erosion of nozzle, electrodes... and validate models. However, establishing a relationship between in-flight measurements and coating properties is another story, whose beginning is just starting (Ref 7). For example, despite the small variability observed in particle state, substantial variability is observed in coating attributes (Ref 5). For that, besides the in-flight measurements, especially particle trajectories distribution, other parameters must be recorded during the spray process, such as the coating mean temperature evolution, the stress distribution evolution, the spray pattern... and also some coating characteristics such as porosity, phase content, oxide content, thermo-mechanical properties..

5.2.1 Coating Monitoring Through In-Flight Particle Parameters. As previously underlined, in spite of many works performed, during the last two decades, there is still no clear relationship between on the one hand in-flight particle parameters, substrate and coating temperature evolution before, during and after spraying and coating thermo-mechanical properties. A factorial design experiment can be performed to link different coating properties such as hardness, oxide content, thickness, porosity, wear resistance... to in-flight particle parameters, coating surface temperature... or spray parameters. For example, it was done by Fris et al. (Ref 164) who found that models based on particle in-flight properties explain the variations 
in the microstructures of plasma-sprayed YSZ as well as or better than the spray gun parameters do. Particle temperatures, $T_{\mathrm{p}}$, and velocities, $v_{\mathrm{p}}$, control the porosity, while the substrate temperature and the spray angle control the cracks formation. However, the strong correlation between $T_{\mathrm{p}}$ and $v_{\mathrm{p}}$ makes it hard to discern where one of these two parameters affects the microstructure features. Basu et al. (Ref 165) and Gevelber et al. (Ref 166) have tried developing real-time control for plasma jets. The aim of their work was to measure in-flight particle parameters, spray pattern, including the spray jet position, and adjust the torch inputs in order to maintain those states at their set point. It is also possible to define a good working area, as did Renault et al. (Ref 167) for plasma-sprayed CuNiIn (Ni 35 wt.\%, In 5 wt.\%) particles $(10-45 \mu \mathrm{m})$. They used the SDC system fixed on a commercial d.c. plasma torch. The parameters given by the SDC were the maximum intensity emitted by hot particles, the position of this maximum relatively to the torch axis, the distribution width as well as the substrate and coating temperature. The powder mass flow rate, the spray pattern, and the relative velocity torch/substrate were kept constant, the only variables being the torch input parameters varied around the standard conditions used by SNECMA Co. A factorial design was constructed. Regression equation were established to relate SDC parameters to coating hardness, oxide content wt.\% and thickness. Figure 29 represents the sensitivity of coating properties to the maximum intensity of hot particles and coating temperature. This figure shows that as soon as the slope of the isovalues is close to be parallel to one of the axes, the coating property studied is very sensitive to the variation of the SDC parameter of the perpendicular axis.

The central zone, surrounded by an ellipse-shaped line, corresponds to the coating properties expected by the manufacturer. As soon as the SDC parameters deviate slightly from this zone, the operator modifies parameters such as the hydrogen flow rate, the carrier gas flow rate, or the cooling airflow rate to keep the SDC parameters in the optimum working zone. This technique has reduced by more than $90 \%$ the number of parts rejected. For other coating properties such as residual stress, measured with the set-up presented in Fig. 21, the main parameter is the coating temperature during spraying. This is illustrated in Fig. 30 showing that by tailoring the temperature variation around that determined by the optimum torch working point, it becomes possible to achieve coatings, which, at room temperature, exhibit either compressive or tensile stress.

Sampath et al. (Ref 7) have shown that "the representation of the particle state within the temperaturevelocity space allows a systematic recognition of the

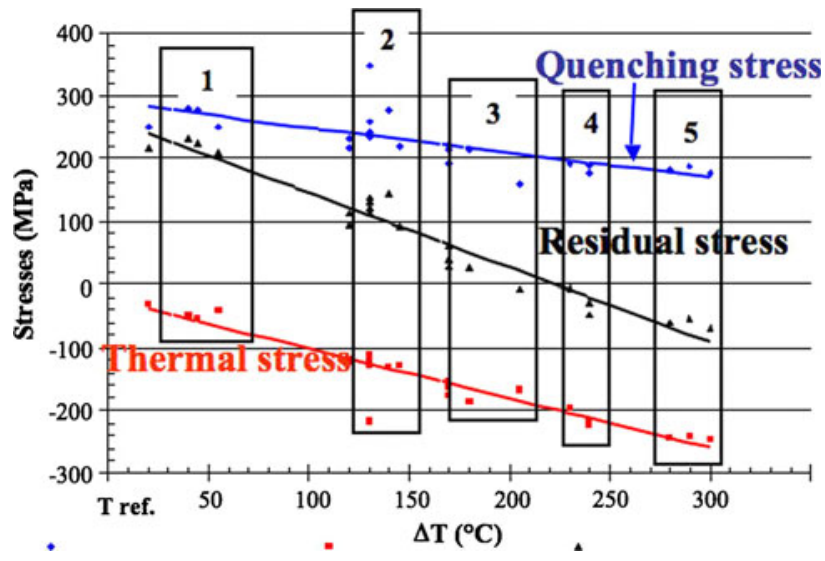

Fig. 30 Effect of the evolution of the coating temperature relatively to the spray temperature on the residual stresses: quenching stress, expansion mismatch or thermal stress, and resulting residual stress of NiCuIn coatings d.c. plasma sprayed (Ref 167)

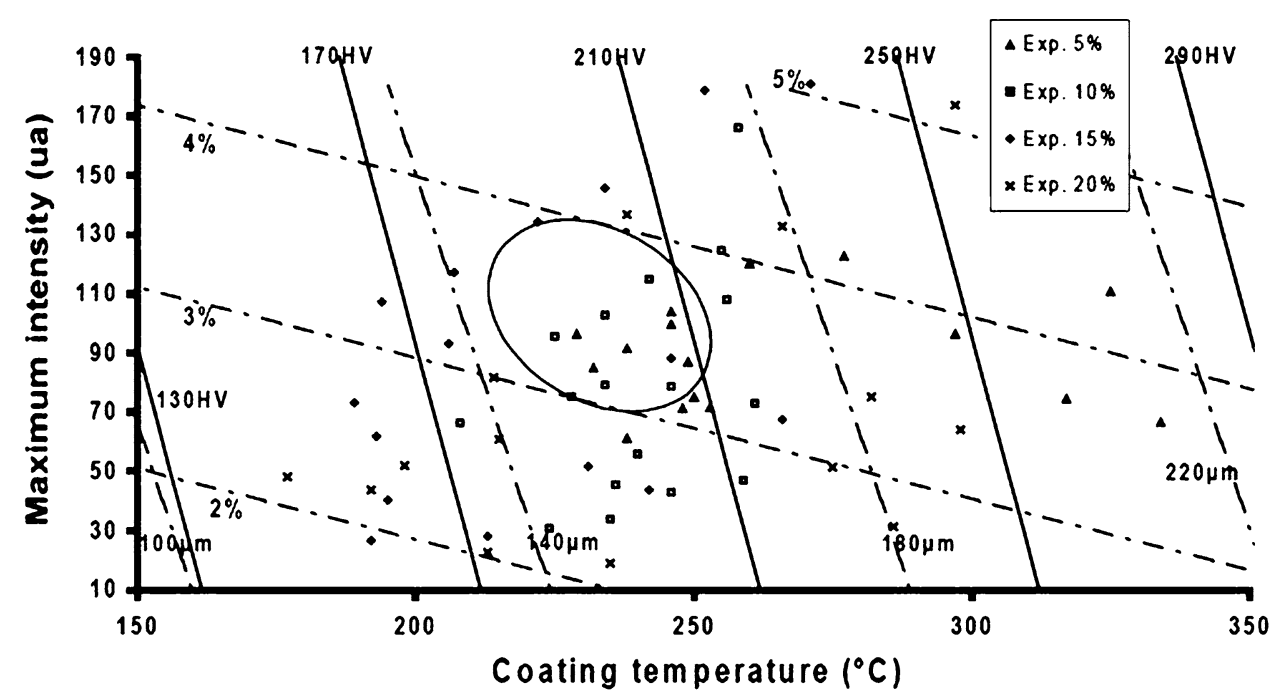

Fig. 29 Sensitivity of coating hardness $\left(\mathrm{HV}_{3}\right)$, oxide wt.\% content and thickness $(\mu \mathrm{m})$ to the maximum intensity of the SDC and coating temperature during d.c. plasma spraying of NiCuIn particles (Ref 167) 
contribution of the process variables and sensitivities." Although elastic modulus is a reasonable quantitative descriptor of a coating property, non-linear response would also have to be considered for porous coatings, especially those subjected to thermo-mechanical loading. "Integrated process maps provide a framework comprehending sensors, enable feedback control and, when combined with coating properties, offer a strategy for coating design" (Ref 7).

5.2.2 Artificial Neural Networks (ANN). Artificial intelligence, based on ANN, proved to be a pertinent tool to predict particle in-flight characteristics and coating structural attributes from the knowledge of processing parameters (Ref 168). A global behavior, based on the sampling of the space parameter correlations, allowed decoupling the effect of code parameters and relating them with representative curves for each particle characteristic. A fuzzy logic controller was implemented to control and regulate the APS processing parameters (arc current intensity, total gas flow rate, hydrogen percentage) to the in-flight particle parameters (Ref 169). ANN was also implemented to predict APS process parameters to manufacture a coating with the desired structural characteristics (Ref 170). The great advantage of ANN over other conventional methods is that it offers a global optimization and does not consider prior assumptions on parameter correlations. However, the constraint to obtain a large representation sample is lowered by considering the noise on the measurements.

\subsection{On-Line Control?}

A real on-line control is still a challenge, because nobody, according to the present knowledge, has a clear idea of the effect of the particle velocities and temperatures at impact on the coating thermo-mechanical properties and especially their service properties. The corresponding strategy for an on-line control could be presented in Fig. 31 (Ref 84) and it should be established for each coating.

\section{Conclusions}

Since the end of the nineties, sensors, able to work in the harsh environment of spray booths, have been developed and commercialized. Most of them are disposed aside the spray torch that implies measuring the in-flight parameters from times to times. On the contrary, sensors, light enough to be fixed on the spray torch, provide information continuously allowing monitoring the torch parameters.

Sensors can follow in-flight particle trajectories, temperatures, velocities, sizes, and shapes. Also, infrared pyrometers or cameras are used to follow substrate and coating surface temperature evolution during their preheating, the spray process and their cooling down. Other sensors permit following the development of stresses within coatings and thickness evolution during their formation. Sensors for in-flight particle parameters can either follow single particles or ensemble of particles. In the first case, more information is obtained with in-flight particle parameters distribution and not only a mean value as with ensemble measurements. Ensemble measurements require a few seconds, while statistical ones need at least a few minutes. All measurements show that the mean values of ensemble measurements are close to those deduced from statistical distributions. Among the in-flight parameters measured, good precisions (5\%) are achieved with velocities and trajectories, which is not the case with temperature. If the relative precision is good (about $5 \%$ ), the absolute value can be obtained with an error of $20 \%$ due to the uncertainties about the emission coefficient and the possible absorption by the particle, especially with ceramics. Moreover, pyrometers must be calibrated regularly and more frequently than other sensors. The precision of particle diameter measurements, based on the light intensity emitted by particles, is also very poor (up to $30 \%$ ). However, they can be calibrated by collecting particles after their flight in the hot gases. New measurements, based on shadowgraph and using laser, allow a good precision on particle diameters and also permit to

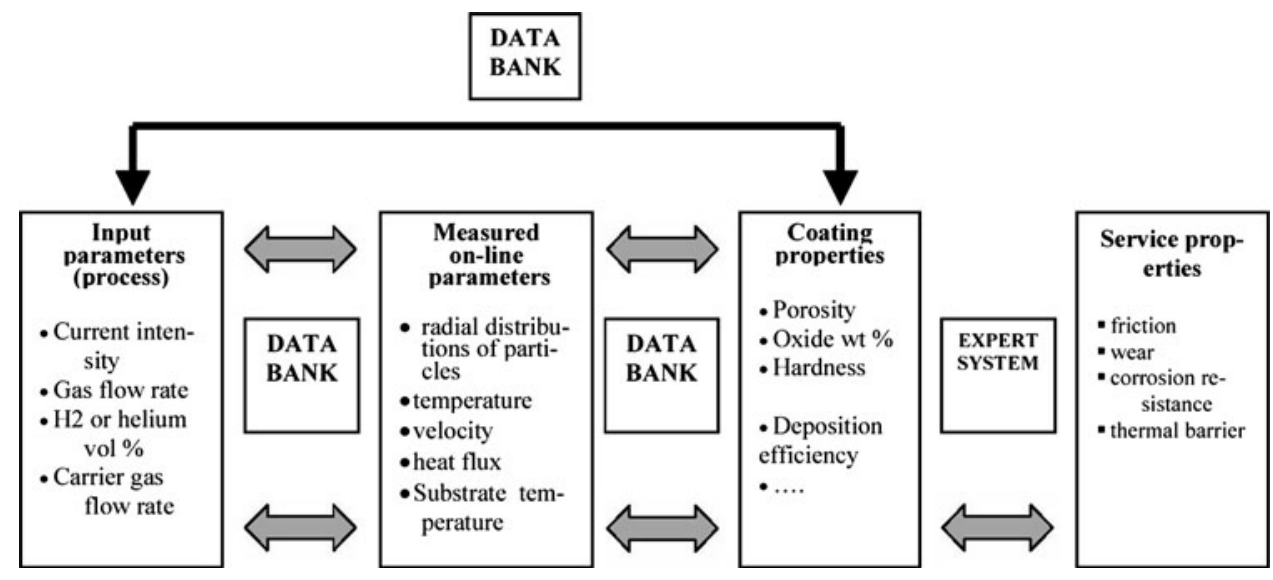

Fig. 31 Strategy of a possible on-line control (Ref 29) 
access to their shape. Such measurements are however limited to particles below $500 \mathrm{~m} \cdot \mathrm{s}^{-1}$. Measurements have also been developed to follow fluxes and velocities of cold particles in-flight by illuminating them with a pulsed laser sheet. For the cold spray process, they allow determining particle velocities. Unfortunately, no device permits measuring the particle diameters in cold spray conditions, which requires either deposition efficiency measurement or counting impacting and rebounding particles to determine the critical velocity. The use of laser illumination has also improved drastically the control the radial injection of cold particles or liquid (suspension or solution spraying) in hot gases.

These sensors have allowed a much better understanding of the influence of the spray gun working conditions on the particles in-flight parameters, especially their temperatures and velocities. For example, the measurement of particle temperatures is one of the key parameters when spraying agglomerated particles made of agglomerated nanometre-sized ones. Everybody agrees on the fact that, since the development of sensors working in spray booths, the coatings reproducibility and reliability have been drastically improved. Moreover, they have improved our knowledge of the spray process by validating models, and, for splat formation, our understanding of coating formation. However, for industrial use these sensors are expensive. However considering the theme of payback, the changes and improvements through in-flight particle control in industries have provided significant savings in material, energy, labor, and hardware while adding to the quality of the product (Ref 171). The author (Ref 171) regrets that at the time little effort was placed on optimizing the process or developing a quantitative return on investment.

The still pending questions are how to optimize the process, achieve a quantitative return on investment, and similarly how to relate such measurements to coating properties. A better understanding of individual splat formation, thanks to dedicated sensors, has been achieved during the last decade for the impact of fully or partially molten particles. It has drastically improved our knowledge about coating formation on the substrate surface. But it is only a part of the story and a lot of work is still necessary to understand and control flattening particles layering. However, for the impact of solid particles (cold spray, HVAF, high power HVOF, D-gun), no such sensor is yet available.

The main difficulty is that coating properties depend on numerous parameters, which are not necessarily, or only partially, controlled by sensors used. The other important parameters are the substrate preparation, the way its preheating modifies the oxide layer (composition and thickness) at metal substrate surface, the spray pattern, the particles oxidation in-flight depending also on the hot gases velocity and composition, particles morphology, which depends on their manufacturing process... Many works are devoted to define "a good working area" through factorial design, using in-flight parameters measurements together with those related to coating generation (temperature, stress formation...) and coating properties. Other approaches, starting from the same parameters, use artificial intelligence based on ANN. However, in spite of the great strides made thanks to sensors used in spray booths, a lot of work is still necessary to achieve a real on-line control of the spray processes. Anyhow the use of sensors has made possible to monitor the spray conditions to achieve a given coating with reliable and reproducible requested properties.

\section{References}

1. J.R. Davis, Ed., Handbook of Thermal Spray Technology, ASM International, Materials Park, OH, 2004

2. Thermal Spraying, Practice, Theory and Application, American Welding Society, Miami, Fl, 1985

3. L. Pawlowski, The Science and Engineering of Thermal Spray Coatings, Wiley, New York, 1995

4. J. Vattulainen, E. Hämäläinen, R. Hernberg, P. Vuoristo, and T. Mäntylä, Novel Method for In-Flight Particle Temperature and Velocity Measurements in Plasma Spraying Using a Single CCD Camera, J. Therm. Spray Technol., 2001, 10(1), p 94-104

5. V. Srinivasan, A. Vaidya, T. Streibl, M. Friis, and S. Sampath, On the Reproducibility of Air Plasma Spray Process and Control of Particle State, J. Therm. Spray Technol., 2006, 15(4), p 739-743

6. M.P. Planche, R. Bolot, and C. Coddet, In-Flight Characteristics of Plasma Sprayed Alumina Particles: Measurements, Modeling, and Comparison, J. Therm. Spray Technol., 2003, 12(1), p 101-111

7. S. Sampath, V. Srinivasan, A. Valarezo, A. Vaidya, and T. Streibl, Sensing, Control, and In Situ Measurement of Coating Properties: An Integrated Approach Toward Establishing Process-Property Correlations, J. Therm. Spray Technol., 2009, 18(2), p 243-255

8. M. Friis and C. Persson, Control of Thermal Spray Processes by Means of Process Maps and Process Windows, J. Therm. Spray Technol., 2003, 12(1), p 44-52

9. L. Leblanc and C. Moreau, The Long-Term Stability of Plasma Spraying, J. Therm. Spray Technol., 2002, 11(3), p 380-386

10. P. Fauchais, J.F. Coudert, and M. Vardelle, Diagnostics in Thermal Plasma Processing, Plasma Diagnostics, Vol 1, O. Auciello and D.L. Flamm, Ed., Academic Press, London, 1989, p 349-446

11. P. Fauchais et al., Diagnostics of Thermal Spraying Plasma Jets, J. Therm. Spray Technol., 1992, 1(2), p 117-128

12. J.R. Fincke, D.C. Haggard, and W.D. Swank, Particle Temperature Measurement in the Thermal Spray Process, J. Therm. Spray Technol., 2001, 10(2), p 255-266

13. C.-J. Li, T. Wu, C.-X. Li, and B. Sun, Effect of Spray Particle Trajectory on the Measurement Signal of Particle Parameters Based on Thermal Radiation, J. Therm. Spray Technol., 2003, 12(1), p 80-94

14. C. Moreau, P. Gougeon, M. Lamontagne, V. Lacasse, G. Vaudreuil, and P. Cielo, On-Line Control of the Plasma Spraying Process by Monitoring the Temperature, Velocity and Trajectory of In-Flight Particles, Thermal Spray Industrial Applications, C.C. Berndt and S. Sampath, Ed., ASM International, Materials Park, OH, 1994, p 431-437

15. M. Prystay, P. Gougeon, and C. Moreau, Correlation Between Particle Temperature and Velocity and the Structure of Plasma Sprayed Zirconia Coatings, Thermal Spray: Practical Solutions for Engineering Problems, C.C. Berndt, Ed., ASM International, Materials Park, OH, 1996, p 517-523

16. M. Vardelle, A. Vardelle, A.C. Leger, P. Fauchais, and D. Gobin, Influence of the Particle Parameters at Impact on Splat Formation and Solidification in Plasma Spraying Processes, J. Therm. Spray Technol., 1995, 4(1), p 50-58

17. P. Fauchais, M. Vardelle, A. Vardelle, and L. Bianchi, Plasma Spray: Study of the Coating Generation, Ceram. Int., 1996, 22, p 295-303

18. P. Fauchais, M. Vardelle, A. Vardelle, L. Bianchi, and A.C. Leger, Parameters Controlling the Generation and Properties of 
Plasma Sprayed Zirconia Coatings, Plasma. Chem. Plasma Process., 1996, 16, p S99-S126

19. P. Wang, S.C.M. Yu, and H.W. Ng, Correlation of Plasma Sprayed Coating Deposition Efficiency with Volume Flux Measurements by Phase Doppler Anemometry (PDA), Plasma. Chem. Plasma Process., 2007, 27, p 311-336

20. J.-G. Legoux, B. Arsenault, L. Leblanc, V. Bouyer, and C. Moreau, Evaluation of Four High Velocity Thermal Spray Guns Using WC- $10 \%$ Co- $4 \%$ Cr Cermets, J. Therm. Spray Technol., 2002, 11(1), p 86-94

21. G. Renouard-Vallet, "Elaboration by Plasma Spraying of Dense and Thin (a Few Tens of Micrometers) Yttria Stabilized Zirconia Electrolytes for SOFCs," Ph.D. Thesis, University of Limoges France, February 8, 2004

22. G. Mauer, R. Vaßen, and D. Stöver, Comparison and Applications of DPV-2000 and Accuraspray-g3 Diagnostic Systems, J. Therm. Spray Technol., 2007, 16(3), p 414-424

23. B.R. Marple, J. Voyer, J.F. Bisson, and C. Moreau, Thermal Spraying of Nanostructured Cermet Coatings, J. Mater. Process. Technol., 2001, 117(3), p 418-423

24. K. Landes, Diagnostics in Plasma Spraying Techniques, Surf. Coat. Technol., 2006, 201, p 1948-1954

25. P. Gougeon and C. Moreau, In-Flight Particle Surface Temperature Measurement: Influence of the Plasma Light Scattered by the Particles, J. Therm. Spray Technol., 1993, 2(3), p 229-233

26. S.P. Mates, D. Basak, F.S. Biancaniello, S.D. Ridder, and J. Geist, Calibration of a Two-Color Imaging Pyrometer and Its Use for Particle Measurements in Controlled Air Plasma Spray Experiments, J. Therm. Spray Technol., 2002, 11(2), p 195-205

27. M.P. Planche, H. Liao, and C. Coddet, Relationships Between In-Flight Particle Characteristics and Coating Microstructure with a Twin Wire Arc Spray Process and Different Working Conditions, Surf. Coat. Technol., 2004, 182, p 215-226

28. J.F. Bissons, M. Lamontagne, C. Moreau, L. Pouliot, J. Blain, and F. Nadeau, Ensemble In-Flight Particle Diagnostics Under Thermal Spray Conditions, Thermal Spray 2001: New Surfaces for a New Millennium, C.C. Berndt, K.A. Khor, and E.F. Lugscheider, Ed., ASM International, Materials Park, OH, 2001, p 705-714

29. T. Streibl, A. Vaidya, M. Friis, V. Srinivasan, and S. Sampath, A Critical Assessment of Particle Temperature Distributions During Plasma Spraying: Experimental Results for YSZ, Plasma. Chem. Plasma Process., 2006, 26(1), p 73-102

30. M. Vardelle, A. Vardelle, P. Fauchais, K.-I. Li, B. Dussoubs, and N.J. Themelis, Controlling Particle Injection in Plasma Spraying, J. Therm. Spray Technol., 2001, 10(2), p 267-284

31. S. Janisson, E. Meillot, A. Vardelle, J.F. Coudert, B. Pateyron, and P. Fauchais, Plasma Spraying Using Ar- $\mathrm{He}-\mathrm{H}_{2}$ Gas Mixtures, J. Therm. Spray Technol., 1999, 8(4), p 545-552

32. M.P. Planche, R. Bolot, O. Landemarre, and C. Coddet, Comparison Between Experimental and Numerical Results Obtained on In-Flight Particles Characteristics, Thermal Spray: Meeting the Challenges of the 21st Century, Vol 2, C. Coddet, Ed., ASM International, Materials Park, OH, 1998, p 355-360

33. R. Bolot, V. Morin, and C. Coddet, Correlation Between Simulations and Plasma Spray Coatings Properties, Thermal Spray 2001: New Surface for a New Millenium, C.C. Berndt, K.A. Khor, and E. Lugsheider, Ed., ASM International, Materials Park, OH, 2001, p 883-888

34. B. Dussoubs, A. Vardelle, G. Mariaux, N.J. Themelis, and P. Fauchais, Modeling of Plasma Spraying of Two Powders, J. Therm. Spray Technol., 2001, 10(1), p 105-110

35. G. Delluc, L. Perrin, H. Ageorges, P. Fauchais, and B. Pateyron, Modelling of Plasma Jet and Particle Behavior in Spraying Conditions, ITSC2004, Modeling and Simulation V, DVS, Düsseldorf, Germany, 2004 (CD-Rom)

36. M. Li and P.D. Christofides, Feedback Control of HVOF Spray Process Accounting for Powder Size Distribution, J. Therm. Spray Technol., 2004, 13(1), p 108-120

37. T. Zhang, D.T. Gawne, and B. Liu, Computer Modelling of the Influence of Process Parameters on the Heating and Acceleration of Particles During Plasma Spraying, Surf. Coat. Technol., 2000, 132, p 233-243
38. A. Devasenapathi, C.B. Ang, S.C.M. Yu, and H.W. Ng, Role of Particle Injection Velocity on Coating Microstructure of Plasma Sprayed Alumina-Validation of Process Chart, Surf. Coat. Technol., 2001, 139, p 44-54

39. J. Wilden, H. Frank, and J.-P. Bergmann, Process and Microstructure Simulation in Thermal Spraying, Surf. Coat. Technol., 2006, 201, p 1962-1968

40. S. Kamnis, S. Gu, and N. Zeoli, Mathematical Modelling of Inconel 718 Particles in HVOF Thermal Spraying, Surf. Coat. Technol., 2008, 202, p 2715-2724

41. L. An, Y. Gao, and T. Zhang, Effect of Powder Injection Location on Ceramic Coatings Properties When Using Plasma Spray, J. Therm. Spray Technol., 2007, 16(5-6), p 967-973

42. H.-B. Xiong, L.-L. Zheng, S. Sampath, R.L. Williamson, and J.R. Fincke, Three-Dimensional Simulation of Plasma Spray: Effects of Carrier Gas Flow and Particle Injection on Plasma Jet and Entrained Particle Behavior, Int. J. Heat Mass Transf., 2004, 47, p 5189-5200

43. P. Fauchais, G. Montavon, and G. Bertrand, Influence of Powders on Thermal Spray Coating Structures: Recent Developments in Nano or Finely Structured Coatings and Some Safety Issues, Thermal Spray 2009: Proceedings of the International Thermal Spray Conference, B.R. Marple, M.M. Hyland, Y.-C. Lau, C.-J. Li, R.S. Lima, and G. Montavon, Ed., ASM International, Materials Park, OH, 2009, p 799-817

44. A. Vardelle, P. Fauchais, B. Dussoubs, and J.N. Themlis, Heat Generation and Particle Injection in a Thermal Plasma Torch, Plasma. Chem. Plasma Process., 1998, 18, p 551-574

45. R. Bandyopadhyay and P. Nylén, A Computational Fluid Dynamic Analysis of Gas and Particle Flow in Flame Spraying, J. Therm. Spray Technol., 2003, 12(4), p 492-503

46. S. Gu, D.G. McCartney, C.N. Eastwick, and K. Simmons, Numerical Modeling of In-Flight Characteristics of Inconel 625 Particles During High-Velocity Oxy-Fuel Thermal Spraying, J. Therm. Spray Technol., 2004, 13(2), p 200-211

47. E. Kadyrov, Gas-Particle Interaction in Detonation Spraying Process, J. Therm. Spray Technol., 1996, 5(2), p 185-195

48. W. Tillmann, E. Vogli, and J. Nebel, Development of Detonation Flame Sprayed Cu-Base Coatings Containing Large Ceramic Particles, J. Therm. Spray Technol., 2007, 16(5-6), p 751-758

49. M.I. Boulos, Heating the Powders in the Fire Ball of an Induction Plasma, IEEE Trans. Plasma Sci., 1978, PS.6, p 93-106

50. M.I. Boulos, The Inductively Coupled R.F. (Radio Frequency) Plasma, Pure Appl. Chem., 1985, 57(9), p 1321-1352

51. M.I. Boulos, RF Induction Plasma Spraying: State-of-the-Art Review, J. Therm. Spray Technol., 1992, 1(1), p 33-40

52. S. Abukawa, T. Takabate, and K. Tani, Effect of Powder Injection of Deposit Efficiency in Plasma Spraying, Proceedings of the 2006 International Thermal Spray Conference, B. Marple et al., Ed., ASM International, Materials Park, OH, 2006 (e-proc)

53. T. Han, Z. Zhao, B.A. Gillispie, and J.R. Smith, Effects of Spray Conditions on Coating Formation by the Kinetic Spray Process, J. Therm. Spray Technol., 2005, 14(3), p 373-383

54. K. Balani, T. Laha, A. Agarwal, J. Karthikeyan, and N. Munroe, Effect of Carrier Gases on Microstructural and Electrochemical Behavior of Cold-Sprayed 1100 Aluminum Coating, Surf. Coat. Technol., 2005, 195, p 272-279

55. M. Vardelle, C. Bossoutrot, T.H. Renault, F. Braillard, and H. Hoffmann, "Dispositif et procédé de contrôle d'une projection thermique," SNECMA Services-SPCTS Laboratory, Published 03/03/2004, Patent n ${ }^{\circ}$ EP:1 340578 A3

56. J. Zierhut, K. Landes, C. Waas, D. Kutscher, P. Heinrich, and W. Krömmer, Particle Flux Imaging, ITSC99 Proceedings, E. Lugsheider, Ed., DVS, Düsseldorf, Germany, 1999, p 340-344

57. J.F. Bisson, B. Gauthier, and C. Moreau, Effect of Plasma Fluctuations on In-Flight Particle Parameters, J. Therm. Spray Technol., 2003, 12(1), p 38-43

58. J.F. Bisson and C. Moreau, Effect of Direct-Current Plasma Fluctuations on In-Flight Particle Parameters: Part II, J. Therm. Spray Technol., 2003, 12(2), p 258-264

59. E. Nogues, M. Vardelle, P. Fauchais, and P. Granger, Arc Voltage Fluctuations: Comparison Between Two Plasma Torch Types, Surf. Coat. Technol., 2008, 202, p 4387-4393 
60. D.L. Gilmore, R.C. Dykhuizen, R.A. Neiser, T.J. Roemer, and M.F. Smith, Particle Velocity and Deposition Efficiency in the Cold Spray Process, J. Therm. Spray Technol., 1999, 8(4), p 576-582

61. B. Jodoin, F. Raletz, and M. Vardelle, Cold Spray Modeling and Validation Using an Optical Diagnostic Method, Surf. Coat. Technol., 2006, 200(14-15), p 4424-4432

62. E. Irissou, J.-G. Legoux, B. Arsenault, and C. Moreau, Investigation of $\mathrm{Al}-\mathrm{Al}_{2} \mathrm{O}_{3}$ Cold Spray Coating Formation and Properties, J. Therm. Spray Technol., 2007, 16(5-6), p 661-668

63. J.G. Legoux, E. Irissou, and C. Moreau, Effect of Substrate Temperature on the Formation Mechanism of Cold-Sprayed Aluminum, Zinc and Tin Coatings, J. Therm. Spray Technol., 2007, 16(5-6), p 619-626

64. W.-Y. Li, C.-J. Li, H.-T. Wang, C.-X. Li, and H.-S. Bang, Measurement and Numerical Simulation of Particle Velocity in Cold Spraying, J. Therm. Spray Technol., 2006, 15(4), p 559-562

65. X.-J. Ning, J.-H. Jang, and H.-J. Kim, The Effects of Powder Properties on In-Flight Particle Velocity and Deposition Process During Low Pressure Cold Spray Process, Appl. Surf. Sci., 2007, 253, p 7449-7455

66. F. Ratetz, "Contribution to the Development of a Cold Gas Dynamic Spray System (C.G.D.S.) for the Realization of Nickel Coatings," Ph.D. Thesis, University of Limoges, France, October 17,2005

67. P. Fauchais, R. Etchart-Salas, C. Delbos, M. Tognovi, V. Rat, J.F. Coudert, and T. Chartier, Suspension and Solution Plasma Spraying of Finely Structured Coatings, J. Phys. D: Appl. Phys., 2007, 40, p 1-13

68. C. Delbos, J. Fazilleau, V. Rat, J.F. Coudert, P. Fauchais, and B. Pateyron, Phenomena Involved in Suspension Plasma Spraying Part 2: Zirconia Particle Treatment and Coating Formation, Plasma. Chem. Plasma Process., 2006, 26, p 393-414

69. P. Fauchais, R. Etchart-Salas, V. Rat, J.F. Coudert, N. Caron, and K. Wittmann-Ténèze, Parameters Controlling Liquid Plasma Spraying: Solutions, Sols, or Suspensions, J. Therm. Spray Technol., 2008, 17(1), p 31-59

70. F. Tarasi, M. Medraj, A. Dolatabadi, J. Oberste-Berghaus, and C. Moreau, Effective Parameters in Axial Injection Suspension Plasma Spray Process of Alumina-Zirconia Ceramics, J. Therm. Spray Technol., 2008, 17(5-6), p 685-691

71. J. Oberste Berghaus, J.-G. Legoux, C. Moreau, R. Hui, C. DeĉesPetit, W. Qu, S. Yick, Z. Wang, R. Maric, and D. Ghosh, Suspension HVOF Spraying of Reduced Temperature Solid Oxide Fuel Cell Electrolytes, J. Therm. Spray Technol., 2008, 17(5-6), p 700-707

72. J. Oberste Berghaus, B. Marple, and C. Moreau, Suspension Plasma Spraying of Nanostructured WC-12Co Coatings, J. Therm. Spray Technol., 2006, 15(4), p 676-681

73. R. Rampon, C. Filiatre, and G. Bertrand, Suspension Plasma Spraying of YPSZ Coatings: Suspension Atomization and Injection, J. Therm. Spray Technol., 2008, 17(1), p 105-114

74. J. Oberste Berghaus and B.R. Marple, High-Velocity Oxy-Fuel (HVOF) Suspension Spraying of Mullite Coatings, J. Therm. Spray Technol., 2008, 17(5-6), p 671-678

75. H. Kassner, R. Siegert, D. Hathiramani, R. Vassen, and D. Stoever, Application of Suspension Plasma Spraying (SPS) for Manufacture of Ceramic Coatings, J. Therm. Spray Technol., 2008, 17(1), p 115-123

76. L. Xie, X. Ma, A. Ozturk, E.H. Jordan, N.P. Padture, B.M. Cetegen, D.T. Xiao, and M. Gell, Processing Parameter Effects on Solution Precursor Plasma Spray Process Spray Patterns, Surf. Coat. Technol., 2004, 183(1), p 51-61

77. D. Chen, E.H. Jordan, and M. Gell, Effect of Solution Concentration on Splat Formation and Coating Microstructure Using the Solution Precursor Plasma Spray Process, Surf. Coat. Technol., 2008, 202, p 2132-2138

78. E.H. Jordan, L. Xie, X. Ma, M. Gell, N.P. Padture, B. Cetegen, A. Ozturk, J. Roth, T.D. Xiao, and P.E.C. Bryant, Superior Thermal Barrier Coatings Using Solution Precursor Plasma Spray, J. Therm. Spray Technol., 2004, 13(1), p 57-65

79. L. Xie, D. Chen, E.H. Jordan, A. Ozturk, F. Wa, X. Ma, B.M. Cetegen, and M. Gell, Formation of Vertical Cracks in Solution Precursor Plasma Sprayed Thermal Barrier Coatings, Surf. Coat. Technol, 2006, 201(3-4), p 1058-1064
80. S. Basu, E.H. Jordan, and B.M. Cetegen, Fluid Mechanics and Heat Transfer of Liquid Precursor Droplets Injected into High Temperature Plasmas, J. Therm. Spray Technol., 2006, 15(4), p 576-581

81. M. Gell, E.H. Jordan, M. Teicholz, B.M. Cetegen, N. Padture, L. Xie, D. Chen, X. Ma, and J. Roth, Thermal Barrier Coatings Made by the Solution Precursor Plasma Spray Process, J. Therm. Spray Technol., 2008, 17(1), p 124-135

82. R. Etchart-Salas, V. Rat, J.F. Coudert, P. Fauchais, N. Caron, K. Wittman, and S. Alexandre, Influence of Plasma Instabilities in Ceramic Suspension Plasma Spraying, J. Therm. Spray Technol., 2007, 16(5-6), p 857-865

83. J. Oberste Berghaus, S. Bouaricha, J.-G. Legoux, and C. Moreau, Suspension Plasma Spraying of Nanoceramics Using an Axial Injection Torch, Thermal Spray Connects: Explore Its Surfacing Potential, E. Lugscheider and C.C. Berndt, Ed., May 2-4, 2005 (Basel, Switzerland), ASM International, Materials Park, OH, 2005 (e-proc)

84. P. Fauchais and M. Vardelle, How to Improve the Reliability and Reproducibility of Plasma Sprayed Coatings, Thermal Spray 2003: Advancing the Science and Applying the Technology, B.R. Marple and C. Moreau, Ed., ASM International, Materials Park, OH, 2003, p 1165-1173

85. L. Li, A. Vaidya, S. Sampath, H. Xiong, and L. Zheng, Particle Characterization and Splat Formation of Plasma Sprayed Zirconia, J. Therm. Spray Technol., 2006, 15(1), p 97-105

86. A.A. Syed, A. Denoirjean, B. Hannoyer, P. Fauchais, P. Denoirjean, A.A. Khan, and J.C. Labbe, Influence of Substrate Surface Conditions on the Plasma Sprayed Ceramic and Metallic Particles Flattening, Surf. Coat. Technol., 2005, 200, p 2317-2331

87. P. Fauchais, M. Fukumoto, A. Vardelle, and M. Vardelle, Knowledge Concerning Splat Formation: An Invited Review, J. Therm. Spray Technol., 2004, 13(3), p 337-360

88. P. Fauchais and S. Chandra, Formation of Solid Splats During Thermal Spray Deposition, J. Therm. Spray Technol., 2009, 18(2), p 148-180, 2317-2331

89. S.C. Gill and T.W. Clyne, Stress Distribution and Material Response in Thermal Spraying of Metallic and Ceramic Deposits, Met. Trans., 1990, 21B, p 377-385

90. R.A. Neiser, M.F. Smith, and R.C. Dykhuisen, Oxidation in Wire HVOF-Sprayed Steel, J. Therm. Spray Technol., 1998, 7(4), p 537-545

91. G. Espie, A. Denoirjean, P. Fauchais, J.C. Labbe, J. Dubsky, O. Schneeweiss, and K. Volenik, In-Flight Oxidation of Iron Particles Sprayed Using Gas and Water Stabilized Plasma Torch, Surf. Coat. Technol., 2005, 195, p 17-28

92. A.A. Syed, A. Denoirjean, P. Fauchais, and J.C. Labbe, On the Oxidation of Stainless Steel Particles in the Plasma Jet, Surf. Coat. Technol., 2006, 200, p 4368-4382

93. F.-I. Trifa, G. Montavon, and C. Coddet, Model-Based Expert System for Design and Simulation of APS Coatings, J. Therm. Spray Technol., 2007, 16(1), p 128-139

94. T. Schmidt, F. Gärtner, and H. Kreye, New Developments in Cold Spray Based on Higher Gas and Particle Temperatures, J. Therm. Spray Technol., 2006, 15(4), p 488-494

95. F. Raletz, "Contribution to the Development of a Cold Spray Process for Spraying Nickel Coatings," Ph.D. Thesis, University of Limoges, France, October 17, 2005

96. V.V. Kudinov et al., High Temp. Dust Laden Jets, VSL, NL, 1981, p 381-392

97. J. Mishin, M. Vardelle, J. Lesinski, and P. Fauchais, Two-Colour Pyrometer for the Statistical Measurement of the Surface Temperature of Particles Under Thermal Plasma Conditions, J. Phys. E Sci. Instrum., 1987, 20, p 255-263

98. P. Gougeon and C. Moreau, Simultaneous Independent Measurement of Splat Diameter and Cooling Time during Impact on a Substrate of Plasma-Sprayed Molybdenum Particles, J. Therm. Spray Technol., 2001, 10(1), p 76-82

99. N.Z. Mehdizadeh, M. Lamontagne, C. Moreau, S. Chandra, and J. Mostaghimi, Photographing Impact of Molten Molybdenum Particles in a Plasma Spray, J. Therm. Spray Technol., 2005, 14(3), p 354-361 
100. R. Dhiman, A. McDonald, and S. Chandra, Predicting Splat Morphology in a Thermal Spray Process, Surf. Coat. Technol., 2007, 201, p 7789-7801

101. W. Trompetter, M. Hyland, D. McGrouther, P. Munroe, and A. Markwitz, Effect of Substrate Hardness on Splat Morphology in High-Velocity Thermal Spray Coatings, J. Therm. Spray Technol., 2006, 15(4), p 663-669

102. R.C. Dykhuizen, M.F. Smith, D.L. Gilmore, R.A. Neiser, X. Jiang, and S. Sampath, Impact of High Velocity Cold Spray Particles, J. Therm. Spray Technol., 1999, 8(4), p 559-564

103. K. Sakaki and Y. Shimizu, Effect of the Increase in the Entrance Convergent Section Length of the Gun Nozzle on the HighVelocity Oxygen Fuel and Cold Spray Process, J. Therm. Spray Technol., 2001, 10(3), p 487-496

104. C.-J. Li, G.-J. Yang, P.-H. Gao, J. Ma, Y.-Y. Wang, and C.-X. $\mathrm{Li}$, Characterization of Nanostructured WC-Co Deposited by Cold Spraying, J. Therm. Spray Technol., 2007, 16(5-6), p 10111020

105. D. Zhang, P.H. Shipway, and D.G. McCartney, Cold Gas Dynamic Spraying of Aluminum: The Role of Substrate Characteristics in Deposit Formation, J. Therm. Spray Technol., 2007, 14(1), p 109-116

106. P. Richer, B. Jodoin, L. Ajdelsztajn, and E.J. Lavernia, Substrate Roughness and Thickness Effects on Cold Spray Nanocrystalline Al-Mg Coatings, J. Therm. Spray Technol., 2006, 15(2), p 246-254

107. V.K. Champagne, Jr., D. Helfritch, P. Leyman, S. Grendahl, and B. Klotz, Interface Material Mixing Formed by the Deposition of Copper on Aluminum by Means of the Cold Spray Process, J. Therm. Spray Technol., 2005, 14(3), p 330-334

108. M. Fukumoto, H. Wada, K. Tanabe, M. Yamada, E. Yamaguchi, A. Niwa, M. Sugimoto, and M. Izawa, Effect of Substrate Temperature on Deposition Behavior of Copper Particles on Substrate Surfaces in the Cold Spray Process, J. Therm. Spray Technol., 2009 (on-line)

109. W.J. Trompetter, M. Hyland, P. Munroe, and A. Markwitz, Evidence of Mechanical Interlocking of NiCr Particles Thermally Sprayed onto Al Substrates, J. Therm. Spray Technol. 2005, 14(4), p 524-529

110. S.V. Klinkov and V.F. Kosarev, Measurements of Cold Spray Deposition Efficiency, J. Therm. Spray Technol., 2006, 15(3), p 364-371

111. F. Hugot, J. Patru, P. Fauchais, and L. Bianchi, Modelling of a Substrate Thermomechanical Behavior During Plasma Spraying, J. Mater. Process. Technol., 2007, 190(1-3), p 317-323

112. F. Monerie-Moulins, "Contribution to the Study of Heat Fluxes Imposed by Plasma Spraying on Substrates and Coatings," Ph.D. Thesis, University of Limoges, 1993

113. E. Lugscheider, F. Ladru, A. Fischer, and C. Herbst, Plasma Sprayed Ceramic Coatings for Electrical Purposes-Necessity of Process Control, Proceedings of the 24th Annual Conference of the IEEE Industrial Electronics Society, Aachen, Germany, 1998, p 2284-2289

114. P. Fauchais, V. Rat, C. Delbos, J. Fazilleau, J.F. Coudert, T. Chartier, and L. Bianchi, Understanding of Suspension dc Plasma Spraying of Finely Structured Coating for SOFC, IEEE Trans. Plasma Sci., 2005, 33(2), p 920-930

115. M. Vardelle, T. Renault, and P. Fauchais, Choice of an IR Pyrometer to Measure the Surface Temperature of a Coating During Its Formation in Air Plasma Spraying, High Temp. Mater. Processes, 2002, 6(4), p 469-490

116. L. Moulla, Z. Salhi, M.P. Planche, M. Cherigui, and C. Coddet, On the Measurement of Substrate Temperature During Thermal Spraying, Thermal Spray Connects: Explore Its Surfacing Potential, E. Lugscheider, Ed., DVS, Düsseldorf, Germany, 2005, p 679-683

117. M. Doubenskaia, P. Bertrand, and I. Smurov, Pyrometry in Laser Surface Treatment, Surf. Coat. Technol., 2006, 201, p 1955-1961

118. W. Xiaa, H. Zhangb, G. Wanga, and Y. Yanga, A Novel Integrated Temperature Investigation Approach of Sprayed Coatings During APS Process, J. Mater. Process. Technol., 2009, 209, p 2897-2906
119. E. Lugscheider, F. Ladru, V. Gourlaouen, and C. Gualco, Enhanced Atmospheric Plasma Spraying of Thick TBCs by Improved Process Control and Deposition Efficiency, Thermal Spray: Meeting the Challenges of the 21st Century, C. Coddet, Ed., ASM International, Materials Park, OH, 1998, p 1583-1588

120. C.J. Friedrich, R. Gadow, A. Killinger, and C. Li, IR Thermographic Imaging-A Powerful Tool for On-line Process Control of Thermal Spraying, Thermal Spray 2001: New Surfaces for a New Millennium, C.C. Berndt, K.A. Khor, and E.F. Lugscheider, Ed., ASM International, Materials Park, $\mathrm{OH}$, 2001, p 779-786

121. C. Verdy, B. Serio, and C. Coddet, In Situ Temperature Measurement Using Embedded Micro-Thermocouples in Vacuum Plasma Sprayed Multi-Layered Structures, Thermal Spray: Meeting the Challenges of the 21st Century, C. Coddet, Ed., ASM International, Materials Park, OH, 1998, p 821-824

122. H.R. Salimijazi, L. Pershin, T.W. Coyle, J. Mostaghimi, S. Chandra, Y.C. Lau, L. Rosenzweig, and E. Moran, Measuring Substrate Temperature Variation During Application of Plasma-Sprayed Zirconia Coatings, J. Therm. Spray Technol., 2007, 16(4), p 580-587

123. S. Kuroda, T. Fukushima, and S. Kitahara, Simultaneous Measurement of Coating Thickness and Deposition Stress During Thermal Spraying, Thin Solid Films, 1988, 164, p 157-163

124. S. Kuroda and T.W. Clyne, The Quenching Stress in Thermally Sprayed Coatings, Thin Solid Films, 1991, 200, p 49-66

125. S. Kuroda, T. Dento, and S. Kitahara, Quenching Stress in Plasma Sprayed Coatings and Its Correlation with the Deposit Microstructure, J. Therm. Spray Technol., 1995, 4(1), p 75-84

126. T.W. Clyne and S.C. Gill, Residual Stresses in Thermal Spray Coatings and Their Effect on Interfacial Adhesion, J. Therm. Spray Technol., 1996, 5(4), p 401-418

127. T. Renault, M. Vardelle, A. Grimaud, P. Fauchais, and H. Hoffman, On-line Control of Particle Spray Jet and Residual Stresses in Plasma Sprays, Thermal Spray: Surface Engineering via Applied Research, C.C. Berndt, Ed., ASM International, Materials Park, OH, 2000, p 1383-1391

128. T. Renault, M. Vardelle, P. Fauchais, H. Hoffmann, and F. Braillard, On-line Monitoring (SDC) Through Coating Surface Temperature of Residual Stresses in APS WC-Co17wt \% Coatings on Hastelloy X, Thermal Spray 2001: New Surfaces for a New Millennium, C.C. Berndt, K.A. Khor, and E.F. Lugscheider, Ed., ASM International, Singapore, 2001, p 743-750

129. S. Sampath and J. Matejicek, Method and Apparatus for Determining Process-Induced Stresses and Elastic Modulus of Coatings by In Situ Measurement, U.S. Patent 6,478,875, 2002

130. J. Matejicek and S. Sampath, In Situ Measurement of Residual Stresses and Elastic Moduli in Thermal Sprayed CoatingsPart 1: Apparatus and Analysis, Acta Mater., 2003, 51(3), p 863-872

131. J. Matejicek, S. Sampath, D. Gilmore, and R. Neiser, In Situ Measurement of Residual Stresses and Elastic Moduli in Thermal Sprayed Coatings-Part 2: Processing Effects on Properties of Mo Coatings, Acta Mater., 2003, 51(3), p 873-885

132. J. Li, R. Bolot, H. Liao, and C. Coddet, Numerical Study of Residual Stresses Formation During the APS Process, Thermal Spray Solutions, Advances in Technology and Application, Osaka, Japan, 2004, ISBN 3-87155-792-7

133. A. Nadeau, L. Pouliot, F. Nadeau, J. Blain, S.A. Berube, C. Moreau, and M. Lamontagne, A New Approach to Online Thickness Measurement of Thermal Spray Coatings, J. Therm. Spray Technol., 2006, 15(4), p 744-749

134. J. Wilden and H. Franck, Theory of Particle Composition Analysis During Thermal Spraying, Proceedings of the ITSC99, E. Lugsheider, Ed., DVS, Düsseldorf, Germany, 1999, p 165

135. K.-I. Li, M. Vardelle, A. Vardelle, P. Fauchais, and C. Trassy, Vaporization of Metal Powders in Plasma Sprays, Thermal Spray: Practical Solutions for Engineering Problems, C.C. Berndt, Ed., ASM International, Materials Park, OH, 1996, p 547

136. A. Vardelle, M. Vardelle, H. Zhang, N.J. Themelis, and K. Gross, Volatilization of Metal Powders in Plasma Sprays, J. Therm. Spray Technol., 2002, 11(2), p 244-252 
137. K.A. Gross, P. Fauchais, M. Vardelle, J. Tikkanen, and J. Keskinen, Vaporization and Ultra-fine Particle Generation During the Plasma Spraying Process, Thermal Spray: A United Forum for Scientific and Technological Advances, C.C. Berndt, Ed., ASM International, Materials Park, OH, 1997, p 543-549

138. J.F. Bisson, C. Moreau, M. Dorfman, C. Dambra, and J. Mallon, Influence of Hydrogen on the Microstructure of Plasma-Sprayed Yttria-Stabilized Zirconia Coatings, J. Therm. Spray Technol., 2005, 14(1), p 85-90

139. B.R. Marple, R.S. Lima, C. Moreau, S.E. Kruger, L. Xie, and M.R. Dorfman, Yttria-Stabilized Zirconia Thermal Barriers Sprayed Using $\mathrm{N}_{2}-\mathrm{H}_{2}$ and Ar- $\mathrm{H}_{2}$ Plasmas: Influence of Processing and Heat Treatment on Coating Properties, J. Therm. Spray Technol., 2007, 16(5-6), p 791-797

140. C. Tekmen, K. Iwata, Y. Tsunekawa, and M. Okumiya, Controlling Graphite Content in Plasma Sprayed Cast Iron Coatings via In-flight Particle Diagnostic, J. Mater. Process. Technol., 2009, 209, p 5417-5422

141. C. Zhang, C.-J. Li, H. Liao, M.-P. Planche, C.-X. Li, and C. Coddet, Effect of In-flight Particle Velocity on the Performance of Plasma-Sprayed YSZ Electrolyte Coating for Solid Oxide Fuel Cells, Surf. Coat. Technol., 2008, 202, p 2654-2660

142. C. Tekmen, Y. Tsunekawa, and M. Okumiya, Effect of Plasma Spray Parameters on In-flight Particle Characteristics and In-Situ Alumina Formation, Surf. Coat. Technol., 2008, 203, p 223-228

143. C. Tekmen, M. Yamazaki, Y. Tsunekawa, and M. Okumiya, In-Situ Plasma Spraying: Alumina Formation and In-flight Particle Diagnostic, Surf. Coat. Technol., 2008, 202, p 4163-4169

144. Z. Yin, S. Tao, X. Zhoua, and C. Ding, Particle In-flight Behavior and Its Influence on the Microstructure and Mechanical Properties of Plasma-Sprayed $\mathrm{Al}_{2} \mathrm{O}_{3}$ Coatings, J. Eur. Ceram. Soc., 2008, 28, p 1143-1148

145. P. Wang, S.C.M. Yu, and H.W. Ng, Particle Velocities, Sizes and Flux Distribution in Plasma Spray with Two Powder Injection Ports, Mater. Sci. Eng. A, 2004, 383, p 122-136

146. J.C. Fang, W.J. Xu, Z.Y. Zhao, and H.P. Zeng, In-flight Behaviors of $\mathrm{ZrO}_{2}$ Particle in Plasma Spraying, Surf. Coat. Technol., 2007, 201, p 5671-5675

147. C. Moreau, Advanced Particle Diagnostics for Controlling Plasma Spray Processes, Sensors and Controls 2004, ASM International, Materials Park, OH, 2004 (e-proc)

148. R.S. Lima and B.R. Marple, High Weibull Modulus HVOF Titania Coatings, J. Therm. Spray Technol., 2003, 12(2), p 240-249

149. R.S. Lima and B.R. Marple, Optimized HVOF Titania Coatings, J. Therm. Spray Technol., 2003, 12(3), p 360-369

150. E. Turunen, T. Varis, S.-P. Hannula, A. Vaidya, A. Kulkarni, J. Gutleber, S. Sampath, and H. Herman, On the Role of Particle State and Deposition Procedure on Mechanical, Tribological and Dielectric Response of High Velocity Oxy-fuel Sprayed Alumina Coatings, Mater. Sci. Eng. A, 2006, 415, p 1-11

151. M.P. Planche, B. Normand, H. Liao, G. Rannou, and C. Coddet, Influence of HVOF Spraying Parameters on In-flight Characteristics of Inconel 718 Particles and Correlation with the Electrochemical Behaviour of the Coating, Surf. Coat. Technol., 2002, 157, p 247-256

152. R.S. Lima and B.R. Marple, Thermal Spray Coatings Engineered from Nano-structured Ceramic Agglomerated Powders for Structural, Thermal Barrier and Biomedical Applications: A Review, J. Therm. Spray Technol., 2007, 16(1), p 40-63

153. F. Ben Ettouil, O. Mazhorova, B. Pateyron, H. Ageorges, M. El Ganaoui, and P. Fauchais, Predicting Dynamic and Thermal Histories of Agglomerated Particles Injected Within a d.c. Plasma Jet, Surf. Coat. Technol., 2008, 202, p 4491-4495

154. R.S. Lima, C. Moreau, and B.R. Marple, HVOF-Sprayed Coatings Engineered from Mixtures of Nanostructured and
Submicron $\mathrm{Al}_{2} \mathrm{O}_{3}-\mathrm{TiO}_{2}$ Powders: An Enhanced Wear Performance, J. Therm. Spray Technol., 2007, 16(5-6), p 866-872

155. R.S. Lima and B.R. Marple, Superior Performance of HighVelocity Oxyfuel-Sprayed Nanostructured $\mathrm{TiO}_{2}$ in Comparison to Air Plasma-Sprayed Conventional $\mathrm{Al}_{2} \mathrm{O}_{3}-13 \mathrm{TiO}_{2}, J$. Therm. Spray Technol., 2005, 14(3), p 397-404

156. R.S. Lima and B.R. Marple, Nanostructured YSZ Thermal Barrier Coatings Engineered to Counteract Sintering Effects, Mater. Sci. Eng. A, 2008, 485, p 182-193

157. M. Gaona, R.S. Lima, and B.R. Marple, Influence of Particle Temperature and Velocity on the Microstructure and Mechanical Behaviour of High Velocity Oxy-fuel (HVOF)-Sprayed Nanostructured Titania Coatings, J. Mater. Process. Technol., 2008, 198, p 426-435

158. R.S. Lima, H. Li, K.A. Khor, and B.R. Marple, Biocompatible Nanostructured High-Velocity Oxyfuel Sprayed Titania Coating: Deposition, Characterization, and Mechanical Properties, J. Therm. Spray Technol., 2006, 15(4), p 623-627

159. B.R. Marple and R.S. Lima, Process Temperature/VelocityHardness-Wear Relationships for High-Velocity Oxyfuel Sprayed Nanostructured and Conventional Cermet Coatings, J. Therm. Spray Technol., 2005, 14(1), p 67-76

160. A. Pourmousa, J. Mostaghimi, A. Abedini, and S. Chandra, Particle Size Distribution in a Wire-Arc Spraying System, J. Therm. Spray Technol., 2005, 14(4), p 502-510

161. R. Bolot, M.-P. Planche, H. Liao, and C. Coddet, A ThreeDimensional Model of the Wire-Arc Spray Process and Its Experimental Validation, J. Mater. Process. Technol., 2008, 200, p 94-105

162. J. Stanisic, D. Kosikowski, and P.S. Mohanty, High-Speed Visualization and Plume Characterization of the Hybrid Spray Process, J. Therm. Spray Technol., 2006, 15(4), p 750-758

163. H. Fukanuma, N. Ohno, Bo Sun, and R. Huang, In-flight Particle Velocity Measurements with DPV-2000 in Cold Spray, Surf. Coat. Technol., 2006, 201, p 1935-1941

164. M. Friis, C. Persson, and J. Wigren, Influence of Particle In-flight Characteristics on the Microstructure of Atmospheric Plasma Sprayed Yttria Stabilized $\mathrm{ZrO}_{2}$, Surf. Coat. Technol., 2001, 141, p 115-127

165. S.N. Basu, G. Ye, C. Cui, M. Gevelber et al., Plasma Sprayed Coatings with Engineered Microstructures, Advancing the Science and Applying the Technology, B.R. Marple and C. Moreau, Ed., ASM International, Materials Park, OH, 2003

166. M. Gevelber, C. Cui, B. Vattiat, Z. Fieldman, D. Wroblewski, and S. Basu, Real Time Control for Plasma Spray: Sensor Issues, Torch Nonlinearites, and Control of Coating Thickness, ITSC 2005 Proceedings, E. Lugsheider, Ed., DVS, Düsseldorf, Germany, 2005 (e-proc)

167. T. Renault, M. Vardelle, P. Fauchais, H. Hoffmann, and F. Braillard, Thermal Spray 2001: New Surfaces for a New Millenium, C.C. Berndt, K.A. Khor, and E.F. Lugsheider, Ed., ASM International, Materials Park, OH, 2001, p 743-749

168. S. Guessasma, G. Montavon, and C. Coddet, Neural Computation to Predict In-Flight Particle Characteristic Dependences from Processing Parameters in the APS Process, J. Therm. Spray Technol., 2004, 13(4), p 570-585

169. A.-F. Kanta, G. Montavon, M.-P. Planche, and C. Coddet, In-flight Particle Characteristics Control by Implementing a Fuzzy Logic Controller, Surf. Coat. Technol., 2008, 202, p 44794482

170. A.-F. Kanta, G. Montavon, M.-P. Planche, and C. Coddet, In-flight and Upon Impact Particle Characteristics Modelling in Plasma Spray Process, Surf. Coat. Technol., 2009, 203, p 33613369

171. M. VandenBergh, Sprayed Particle Diagnostics, Spraytime, 2009, 16(1), p 9-12 